\title{
ECONOMICS
}

\section{Development and Interdisciplinarity: a Citation Analysis}

\author{
by
}

Sophie Mitra,

Department of Economics, Fordham University

Michael Palmer

Economics Discipline, Business School, University of Western Australia

and

Vu Anh Vuong

Economics Discipline, Business School, University of Western Australia 


\title{
Development and interdisciplinarity: a citation analysis
}

\author{
Sophie Mitra ${ }^{1}$, Michael Palmer ${ }^{2}$, and Vu Anh Vuong ${ }^{2}$ \\ ${ }^{1}$ Department of Economics, Fordham University, NY, USA \\ ${ }^{2}$ Department of Economics, University of Western Australia, Perth, Australia
}

\begin{abstract}
Development is often defined as an inherently interdisciplinary field of study. Yet there has been limited examination of this interdisciplinarity. Using Web of Science data, we present citation patterns since 1990 between leading journals of two fields of development, development economics and development studies, and other social science disciplines (economics, geography, political science and sociology). We find negligible interdisciplinary interactions in development, with the bulk of cross-disciplinary citations taking place between development economics, development studies, and economics. There exists an increasing trend since the mid-2000s in the number of citations between development economics and development studies. We explore a number of potential contributing factors and conclude that the most likely explanation is rising numbers of economists publishing in development studies journals in response to increasing relative competition in development economics journals. Notwithstanding, cross-citation rates between the two development fields remain low at two-three percent. Overall, results suggest that development is not an interdisciplinary field of study as measured by flows of citations.
\end{abstract}

Key words:

Development; Interdisciplinarity; Development Studies; Development Economics; Social Sciences 


\section{Introduction}

Definitions of what constitutes the field of development research vary. The European Association of Development Research and Training Institutes defines the field of development studies as a "multi- and inter-disciplinary field of study that seeks to understand social, economic, political, technological, ecological, gender and cultural aspects of societal change at the local, national, regional and global levels and the interplay between these different levels and stakeholders involved." As noted by Madrueno \& Tezanos (2018), this definition is broad and not without criticism. What is less disputed is its interdisciplinary nature which requires the collective insights of different academic disciplines. In development economics, the importance of interdisciplinary exchanges is also well noted. In their textbook, Development Economics: Theory and Practice, Alain De Janvry and Elisabeth Sadoulet (2016; p.24) argue that development economics is distinct as a field of economics: "it is uniquely integrative as the many dimensions of economics have to be brought together and related to other disciplines... Development economists thus require depth in the tools of their trade and breadth in the multiple dimensions of the development problem, both across fields of economics and across disciplines not only in the social sciences but beyond."

This article examines to what extent different fields of development, development studies (DS) and development economics (DE), draw upon the work of other social science disciplines and of each other and how this has changed over time. To gain further insights we look at the extent to which other disciplines are influenced by development research. Interdisciplinarity in development research has thus far been tackled through discussion (e.g. Kanbur, 2002, Harriss, 2002). We capture interdisciplinary engagement through citations, in that citations may reflect flows of scholarship across disciplines. Citation analysis has been used as a tool to describe the flow of information and exchanges among journals in a discipline and across disciplines (Pieters and Baumgartner, 2002). In this paper, going back to 1990, we present an analysis of citation patterns between the top-five DS and DE journals as well as top generalist journals in other 
disciplines that do development research: sociology, anthropology, political science, and geography.

Overall, we find limited citation flows between DE, DS and other social science disciplines, with the bulk of cross-disciplinary citations taking place among the two development fields and economics. The level and growth of citations from DS to DE is considerably higher than the reverse yet mitigated somewhat when weighted by the total number of citations. DS increasingly cites economics and to a more limited extent political science and geography while DS gets cited in geography and to a smaller extent in political science. DE overwhelmingly cites economics in increasing frequency and to a much more limited extent political science while DE gets cited in economics, and political science and anthropology to a lesser extent. We observe a clear break in the trend of cross-citations between DS and DE with the number of citations increasing significantly since the mid-2000s. We find evidence of a disproportionate rise in the volume of papers published in development studies (with a rising number of citations per paper) since the mid-2000 period and a corresponding increase in the number of economists publishing in development studies journals. While there appears to be growing communications among different fields of development cross-citation rates remain very low at two-three percent of total citations and are driven by select journals.

This paper contributes to the literature on the inter-disciplinary engagement of development research in several ways. First, with respect to development economics, there has been a growing interest in the interactions of economics with other disciplines (Angrist et al., 2020, Fourcade et al., 2015, Pieters and Baumgartner, 2002). In their paper, titled The Superiority of Economists, Fourcade, Ollion and Algan (2015) present the relationship between economics and other social science disciplines as one of insularity and dominance: over the 2000-2009 period, their citation analysis of flagship journals in economics, political science and sociology indicate asymmetric flows between economics and the other social sciences. Recently, Angrist et al. (2017) find that 
economics is increasingly likely to reference other social sciences, but like earlier studies has analogous results with economics being more heavily referenced in other social sciences which the authors interpret as indicative of a rise in the extramural influence of economics research. Does this hold for fields of economics that are potentially more interdisciplinary such as development economics? Interactions between economics and other disciplines may vary across fields. It is important to assess what the situation is in development economics since, as noted earlier, development economics is argued to be a distinct field requiring interdisciplinary knowledge and insights (de Janvry and Sadoulet, 2016; Kanbur, 2002). The picture of insularity and dominance painted by Fourcade et al (2015) may not hold for development economics. In addition, we examine the relationship between economics and an inherently inter-disciplinary field, that of development studies. Earlier citation analyses focused on economics in interaction with singular social science disciplines. This provides a different lens through which to view the interdisciplinary interactions of economics, that could potentially be used for further analyses of economics in relation with other interdisciplinary fields such as public health, urban studies, women studies.

In addition, this paper contributes to understanding the role of disciplines and journals in forming the contemporary international development discourse. There exists a relatively large literature discussing what development studies is about and what makes it distinctive (e.g. Loxley, 2004, Ziai, 2015, Tezanos Vázquez and Sumner, 2013, Madrueño and Tezanos, 2018). Previous literature, by and large, has not examined development studies journals. Madrueno \& Tezanos (2018) undertake a cluster citation analysis from four development studies journals to identify research interests over the last 15 years, as well as the most influential countries, institutions and languages. ${ }^{1}$ We build on this research by presenting citation patterns from leading development studies journals to other disciplines, and vice-versa, to examine citation patterns in the field of development studies over the last three decades. 


\section{Data}

We use the Web of Science to construct a database of all articles published for the core journals in each discipline over the 1990-2019 period.

Using this dataset of aggregated citations for the core journals of each discipline, our citation analysis proceeds in several steps. We first present cross-citation patterns between development economics (DE) and development studies (DS), both in terms of the absolute number of citations and the proportion of total citations. We do this both for the core journals and individual journals. Next, we extend the cross-citation analysis to other social science disciplines. Consistent with other studies, we analyse disciplines and fields through their core journals. We do not consider books, conference proceedings and refereed working papers. We focus on articles published in core journals in a discipline and their citations of articles in the core journals of other disciplines. We concentrate on the core five journals since interdisciplinary citation flows have been shown to be driven by a few journals only (Miller, 1997, Pieters and Baumgartner, 2002). By drawing upon five of the most influential journals for each discipline we anticipate to capture the majority of citation flows. Indeed, we test the sensitivity of our results against the top ten journals from each discipline and the results are qualitatively unchanged (these results are available upon request).

To investigate the drivers of trends, we draw upon other data sources. We match aggregated data on the core five journal articles in each discipline published in the Web of Science over the period 1991-2018 to Journal of Economic Literature (JEL) $\operatorname{codes}^{2}$ contained in the EconLit database. In addition, we draw upon historical submission data obtained from personal communication with the editors and editorial staff of the top five development economics and the top five development studies journals. Information was requested on the number of annual submissions, desk rejections and final acceptance rates. Information supplied varied across the journals. Finally, for further analysis we draw upon detailed bibliographic data on author institutional affiliations found in the $W e b$ of Science electronic database. 


\subsection{Selection of Core Journals}

We compiled a list of core journals starting from the list of journals in the Social Sciences Citation Index (SSCI) published by the Institute for Scientific Information (ISI) in DE, DS and in each social science: economics, anthropology, geography, political science and sociology. We excluded from these lists journals which specialise in a specific country or region or in a subfield (e.g. environment or sustainability). As we are primarily interested in citation flows between DE, DS and other disciplines, we focused on journals indexed in EconLit. EconLit is a database developed and maintained by the American Economic Association that indexes journals in economics and related social sciences. It is widely used in economics and is usually where scholars in economics access the literature. One relatively highly ranked journal from the development studies list (Third World Quarterly) was not indexed in EconLit and thus removed. For all disciplines, we checked the mission statement for each journal on its website to ensure that the journal's stated mission is in line with the discipline the journal was categorized in. Finally, we ranked journals by their five-year impact factor as published in the SSCI and selected as core those in the top five.

It should be noted that to compile the DS core journal list, we went through additional steps. As DS is inherently interdisciplinary, we checked the disciplinary composition of the editorial board members to ensure that they do not predominantly belong to a single discipline such as economics. In addition, for the generalist journals in the social sciences, we cross checked with colleagues working in these disciplines to ensure that our core journals can be viewed as top general interest journals and do not belong to a discipline sub-field. For economics, we followed the well-known 'top five' general interest economics journals included in previous citation analyses in economics (Ellison, 2002, Heckman and Moktan, 2018). 
Table 1 displays the core journals selected for DE, DS, anthropology, economics, geography, political science and sociology ranked by 5 -year impact factor. Table 1 also shows the total number of citations for each journal in 2018, the year each journal was established and the year it was indexed by WoS. The core journals for DE are: Journal of Development Economics (JDE), World Bank Research Observer (WBRO), World Bank Economic Review (WBER), Economic Development and Cultural Change (EDCC) and Review of Development Economics (RDE). The core journals for DS are: World Development (WD), Development and Change (DC), Journal of Development Studies (JDS), Journal of Human Development and Capabilities (JHDC) and Development Policy Review (DPR). For both DE and DS, there exists a clear leader with respectively JDE and WD experiencing significantly higher citations than other core journals.

\section{Cross-citations}

\subsection{Social Science Citations in Development Economics and in Development Studies}

We examine trends in the level of citations of articles in generalist journals in several social sciences found in DE and DS in Figure 1a and 1b respectively. DE and DS have increasingly cited economics. Starting with DE, Figure 1a shows that DE started from a level of about 200 economics citations in 1990 to above 1600 economics citations in 2018, representing an eight-fold increase. An increase in political science is noteworthy though since 2012. Citations of social sciences other than economics in DE have remained negligible. In 2018, for instance, DE made seven citations to anthropology, 16 citations to sociology, 36 citations to political science, and six citations to geography; a combined total of 65 citations. Moving onto DS in Figure 1b, DS cites economics most and increasingly so. As to other disciplines, there is little to note for the two decades prior to 2010 before a recent trend emerges in the level of citations of political science since 2015 and geography since 2017. However, relative to economics, the number of citations to other social sciences remains modest. In 2018, in DS, the political science and geography citations was just one-sixth of the number of economics citations. Like DE, DS draws substantially on 
economics and less on other social sciences. Overall, DE and DS cite generalist social science journals in a negligible manner except for economics which has been increasingly cited in both DE and DS, and especially since 2008 for DS.

\subsection{Development Economics and Development Studies Citations in Social Sciences}

We now analyse whether generalist social science core journals cite DE and DS. Figures 2a and $2 \mathrm{~b}$ respectively illustrate the levels of DE and DS citations in the social sciences. Both DE and DS receive negligible citations in the social sciences. There is a gradual rising trend in the volume of DE citations in economics, from a low of 11 citations in 1990 to a high of 95 citations in 2018

(Fig 2a). However, economics barely cites DS with a total of only 12 citations in 2018.

Geography is the social science that cites DS the most, with a sharp increase in 2010-2013. In 2018, there were 105 DS citations in geography, compared to 35 in political science, 5 in sociology and 11 in anthropology. Comparing Figure 2 to Figure 1, economics cites DE and DS far less than the other way around. Overall, since 1990, DE and DS have increasingly been cited in economics and geography respectively, and DE and DS citations in other social sciences have remained limited.

\subsection{Cross-citations between Development Economics and Development Studies}

Table 2 gives the cross-citations from DE to DS and vice versa over the 1990-2018 period. There were 3,434 citations of DS papers in DE journals (DS citations in DE) and 10,351 citations of DE papers in DS journals (DE citations in DS). At the same time, DS journals tend to have a much larger volume of citations. The total number of citations in DE and DS core journals stood at 160,378 and 413,211 respectively. It is then important to analyse cross-citations in relative terms. Citations of DE articles account for $2.51 \%$ of citations in DS while citations of DS articles account $2.14 \%$ of citations in DE. Table 2 also shows the ratio of the share of DS citations in DE to the share of DE citations in DS. Parity in this ratio indicates that the two fields cite each other at the same rate whereas a value higher than (less than) one indicates that 
DE cites DS at a relatively higher (lower) rate. The ratio stands at 0.85 , indicating that over the 1990-2018 period, DE has cited DS at a lower rate. In addition, it is noteworthy that most of the cross-disciplinary citations are driven by five of the core journals: JDE, EDCC and WBER in DE, and WD and JDS in DS. In fact, based on the number of citations in Table 2, 95\% of DS citations in DE are citations of JDS and WD papers and $88 \%$ of DE citations in DS are citations of JDE, EDCC and WBER papers. Overall, cross-disciplinary citations between DE and DS account for a negligible share of total citations and mainly come from a handful of journals. It also suggests a somewhat asymmetrical relation with DS citing DE a bit more than the reverse.

Table 2 presents the stack of cross citations over three decades. Table 3 breaks them down by decade. Table 3 shows an increase in the number and rate of cross citations. The increase was more pronounced from DS to DE leading to an asymmetry in the 2010s. The share of DS citations in DE increased from $1.95 \%$ in the 1990 s to $2.11 \%$ in the 2010 s, while the share of DE citations in DS went up from $2.02 \%$ in the 1990 s to $2.74 \%$. In DS, WD and JDS have consistently accounted for the large majority of the DE citations. In DE, the bulk of DS citations are in JDE and EDCC. RDE, WBER and WBRO grew in the number of DS citations over the decades. Overall, results shows a modest increase in cross-citations over time and more recently, WD, JDS, JDE and RDE are the four leading sources of cross citations. The bottom of Table 3 shows the cross-citation ratio for each decade. Cross-citations grew faster in DS compared to DE leading to a cross citation ratio declining from 0.96 in the 1990 s to 0.91 in the 2000 s and 0.81 in the 2010 s.

Figure 3 shows cross-citations annually over the 1990-2018 period. Figure 3a and 3b focus on DS citations in DE and show the breakdown by citing DE journal and cited DS journal. In 3a and $3 b$, the upper line is the same: it shows the total DS citations in DE. In Figure $3 c$ and $3 d$, the upper line shows the total DE citations in DS with the breakdown by cited DE journal and 
citing DS journal . Since 1990, DS has consistently cited DE more than DE has cited DS. From 1990 to the mid-2000, levels of cross citations were steady for both DE and DS. Since 2008/2009 respectively, DS and DE have increasingly cited each other, with a rate of growth that is sharply higher for DE citations in DS than for DS citations in DE. DS citations in DE increased from around 50 citations in the early 1990s to around 350 citations in 2018, representing a seven-fold increase. DE citations in DS rose from a low of around 100 citations in 1990 to a peak of 900 citations in 2018, representing a nine-fold increase. Looking at the breakdown by journal in Figures $3 \mathrm{a}$ and $3 \mathrm{c}$, the growth of DS citations in DE comes from two journals, JDE and RDE and in Figures $3 \mathrm{~b}$ and $3 \mathrm{~d}$ the growth in DE citations in DS comes largely from two journals, WD and JDS.

Comparing Figure 3a to Figure 1a, DE cites economics twice more than it cites DS, but cites DS more than non-economics social sciences. These results overall suggest that DE draws heavily from economics and very little from other disciplines outside of DS, in fact outside two DS journals, WD and JDS. Comparing Figure $3 c$ to Figure 1b, DS cites economics more than it cites DE and citation patterns to economics and DE track each other closely over time and emerge strongly from the mid-2000 period. Putting together Figure 3 and Figure 2, out of all disciplines, the largest number of DE citations is found in DS and vice versa. This is particularly the case for DE where the number of citations received from DS far outweighs those received from economics and other social sciences. Figure 3 e presents the cross-citation ratio on an annual basis since 1990. The ratio is highly variable oscillating between values above and below one until around 2007 before a sustained fall to a low of 0.56 in 2015 and a recent increase since 2016 up to 1.02 in 2018. Thus for the 2007-2015 period, DS outstripped DE in cross-citations, whereas since 2016 the trend has reversed towards parity. 
There are several noteworthy limitations of the analysis above and opportunities for future research. Our analysis for the most part is limited to aggregated citations across five journals for each field/discipline. We did increase the list of core journals to 10 for DS and results were largely similar (Appendix Table 1, Figures 4-6). What is important to note is that when we dropped WD and JDS from the analysis, the trend results were changed substantially. Indeed, cross citations between DE and DS are then almost non-existent and the growing trend in cross citations since the mid 2000s vanishes.

All in all, results from the citation analysis suggest that in development research there is insularity as we find negligible interdisciplinary cross-citations with the bulk of cross-disciplinary citations taking place between economics and DE/DS and between DE and DS. In particular, for DE and DS, cross-disciplinary citations are limited to $2.14 \%$ of citations in DE going to DS articles and $2.51 \%$ of citations in DS going to DE articles. Cross-citations are to some extent asymmetrical with DS citing DE more than DE citing DS. Since the mid-2000s, we find an increasing trend in the number of citations from DE to DS and from DS to DE. This trend does not suggest deepening interactions between DE and DS as it is limited to few journals. In fact, the interplay between DE and DS is driven largely by JDS, WD in DS and by JDE and RDE in DE. Unlike the results of Fourcade et al (2015) on the dominant position of economics with respect of other social sciences in the US, our analysis suggests that DE does not dominate DS in terms of citation. Next, we investigate the drivers of the growing cross-citation trend between DE and DS since the mid2000s.

\section{Why have development economics and development studies increasingly cited each other since the mid-2000s?}

We investigate several mechanisms that could potentially be at play behind the growing trend in cross-citations between DE and DS.

\subsection{Changes in research fields}


The documented rise in cross-citations between DE and DS might be explained by changes in published fields of research. It is conceivable that DE may be publishing increasingly in fields which require collective insights from different academic disciplines or that DS may be publishing increasingly in fields which traditionally have been the domain of economists. To assess the importance of field composition, we classify articles according to Journal of Economic Literature (JEL) codes contained in the American Economic Association's EconLit database. We match articles in the Web of Science database to JEL codes found in the EconLit database (Card and DellaVigna, 2013, Angrist et al., 2020). We matched 92\% of Web of Science articles in DE journals and 93.4\% of articles in DS to the EconLit database over the period from 1991 to 2018. Articles can reference up to five JEL codes which fall within a broader set of JEL categories. ${ }^{3}$ Figure 4 shows the JEL codes in DE and DS over time. ${ }^{4}$ For both DE and DS, Economic Development is the dominant field of research, although for DE (Figure 4a), there has been a clear decline for this field. In both DE and DS, three fields have been growing: (i) Microeconomics (ii) Health, education and welfare, and (iii) Labour and demographic. For DS (Figure 4b), an additional field experiencing growth is Agriculture \& Environmental. Similar results were found when we limited DS to articles published in the two journals that are major drivers of trends in DS in Figure 3 (WD and JDS).

These changing trends in the composition of research fields is consistent with DE increasingly publishing in fields which are inherently more interdisciplinary in nature, such as health and education, which may contribute to trends in cross-citations. However, contrary to cross-citation patterns illustrated in Figure 3 there exists no apparent secular change in research fields from the mid-2000 period when the sustained increase in cross-citations started. Changing research fields do not seem to be the primary driver of growing cross-citations since the mid-2000s.

\subsection{The volumes of articles and citations}


The volume of published and cited development research may have grown differentially in DS and in DE thus leading to changes in cross-citations. Figure 5 shows that there has been a growth in citations in DE and an even larger growth in DS. For DS, the growth is very pronounced since 2005. This is explained by higher growth in the number of articles published in DS compared to DE as well as higher number of citations per article (Appendix Figures 1 and 2). The larger growth in the volume of citations in DS may explain the larger increase in DE citations in DS compared to DS citations in DE. As shown in Appendix Figure 1, there exists a clear break in the trend of articles published in the core DS journals from the mid-2000 period. Since this period, the annual number of articles published in DS increased three-fold compared to a two-fold increase for DE. It is shown further in Appendix Figure 3 that the bulk of this increase derives from $W D$ and the $J D S$; the very two journals that often cite DE. The decline in the cross-citation ratio in Table 3 may reflect to some extent these differential patterns in volumes of articles and citations in DE and DS over time.

\subsection{Changes in where economists publish in development}

The top-five journals in economics have experienced significant growth in the number of submissions which combined with a reduction in the number of published papers has resulted in a significant reduction in acceptance rates at these journals (Card and DellaVigna, 2013). One hypothesis that we explore below is whether the same trends of increasing competition have occurred in DE relative to DS which may have led to a spill-over of economists publishing in DS and a subsequent increase in cross-citations between the two fields. First, we compare levels and trends in article acceptance rates of select journals from data obtained from journal editors and editorial staff. Second, we examine trends in author affiliations in 'Economics' registered to articles published in the top-five development studies journals obtained from bibliometric data from Web of Science. 
As shown in Figure 6, acceptance rates of the three DE journals for which data could be obtained are all below 10 percent. WBER has experienced a notable decline in acceptance rates from 16 percent in 2005 to just 5 percent a decade later before increasing to 7 percent in 2018. This is partly because of a more than doubling in the number of submissions to the journal over the last decade (McKenzie, 2019). EDCC experienced a small rise in acceptance rates from 3 to 5 percent over the six year period from 2013 to 2018. Similarly, JDE acceptance rates have risen from 6 to 8 percent over the three years from 2016 to 2018. For DS, the acceptance rates are generally higher at 10 percent or above (Figure 7). In 2000, JDS had an acceptance rate of over 20 percent which has declined to 14 percent in 2013 (recent years are unavailable). Acceptance rates at DPR have oscillated around 20 percent since the first data point of 2008 with a spike of up to 45 percent in 2016. WD is an exception experiencing a downward trend in acceptance rates from 17 percent in 2013 to 9 percent in the year 2018. The journal has received a dramatic increase in the annual number of submissions, the number more than doubling from 1,282 in 2011 to 2,864 in $2018 .^{5}$ In response, the journal has significantly increased the number of articles published in recent years yet not enough to offset falling acceptance rates (McKenzie, 2019).

Figure 7 illustrates annual frequencies of authors with an economics affiliation in articles published in DS journals over the 1990-2018 period. For most of the 1990s, not a single author referenced an economics affiliation. The number of authors with an economics affiliation remained below fifty until 2007 before a sustained increase to approximately 200 authors in 2017 and a jump to 300 authors in 2018. The rising trend is consistent when adjusting for the annual number of articles published. ${ }^{6}$ Moreover, the structural break in the mid-2000 period is similar with the pattern of cross-citations from DS to DE as illustrated in Figure 1. As illustrated further in Figure 7, the bulk of the authors with an economics affiliation are publishing in JDS and WD, the very two journals that have accounted for the majority of cross-citations between DE and DS in Figure 3. There is a jump in the number of economists publishing in WD in 2018 which corresponds to recent exponential growth in citations from DE to the journal. 
Overall, our findings provide suggestive evidence that increasing competition in DE journals may have led economists to publish in increasing numbers in DS journals, namely the JDS and $W D$. The timing of this phenomenon is consistent with the surge in cross-citations between DE and DS of Figure 3. The question remains why this occurred systematically from the mid-2000 period. Unfortunately, we do not have journal acceptance rate (or article submission) data dating back that far. Together these findings imply that one significant pathway through which DE interacts with DS is through economists publishing in selected DS journals.

\section{Conclusion}

This article explores citation flows between DE, DS and other social sciences. Drawing upon citation data from the core five journals for each discipline over three decades, we identify several patterns and trends.

First, we find limited interdisciplinary interactions in development as measured by citations, with the bulk of cross-disciplinary citations taking place between DE, DS and economics. Among the social sciences, DE gets cited and heavily cites general interest economics journals but its interactions with other social sciences are negligible. DE rarely cites from the core journals in anthropology, sociology, political science and geography. DS increasingly cites economics and to a more limited extent political science and geography while DS gets cited in geography and to a smaller extent in political science. In spite of sizeable and rising citations to mainstream economics journals from DS, economics in turn does not cite DS.

Second, for DE and DS, cross-disciplinary citations are limited to $2.18 \%$ of citations in DE going to DS articles and $2.58 \%$ of citations in DS going to DE articles. Cross-citations have been somewhat asymmetrical with DS citing DE more than DE citing DS. Unlike the results of Fourcade et al (2015) on the dominant position of economics with respect of other social sciences in the United States, our analysis suggests that DE does not dominate DS in terms of citation. 
Third, most cross citations between DE and DS come from few journals. The interplay between DE and DS is driven largely by JDS, WD in DS and JDE and RDE in DE.

Fourth, since the mid-2000s, we find an increasing trend in the number of citations from DE to DS and from DS to DE. This trend does not suggest deepening interactions between DE and DS as it is limited to few journals.

Fifth, we explore factors of the growth in cross-citations between DE and DS since the mid2000s. We find support for two explanations: (i) a disproportionate rise in the volume of papers published in DS with a rising number of citations and (ii) an increase in the number of economists publishing in DS, likely in response to growing competition in DE journals. Results overall suggest that citation wise, DE is insular but does not dominate DS.

Of course, our findings are limited to citation patterns in academic journals. Future research would benefit from analyses that include other publication types, such as books and conference proceedings and other ways to examine the extent of interdisciplinary interactions between DE, DS and the social sciences. Nonetheless, we contribute to the literature on the development discourse (Loxley, 2004, Ziai, 2015, Tezanos Vázquez and Sumner, 2013, Madrueño and Tezanos, 2018). We document rising economics and DE citations in DS journals, in part due to rising numbers of economists publishing in WD and JDS.

Our findings also contribute to the on-going discussion about economics and interdisciplinarity (Pieters and Baumgartner, 2002, Angrist et al., 2020, Fourcade et al., 2015). Angrist et al. (2020) document a clear rise in extramural influence of economics research through growing citations in other disciplines, while also showing that economics is increasingly likely to reference other social sciences. They attribute the increasing reach of economics to growth in citations to empirical work owing to advancements in economic methods, specifically the increased use of randomised control trials and quasi-experimental methods. Our findings for the development field are less flattering for economics than in Angrist et al (2020). While we also find a shift in 
research fields towards more applied fields in development, our findings do not support the idea that DE's influence in other disciplines might be growing through increasing citations. Instead, we find a new and previously unexplored pathway to interdisciplinary interactions in the spillover of economists publishing outside of economics.

Finally, our findings add to the literature on interdisciplinarity in the social sciences. Although we are at a time when universities and donors encourage interdisciplinary research, the negligible interdisciplinary interactions found in a citation analysis point towards disciplinary silos in development research, 


\section{References}

ANGRIST, J., AZOULAY, P., ELLISON, G., HILL, R. \& LU, S. F. 2020. Inside job or deep impact? Using extramural citations to assess economic scholarship. Journal of Economic Literature, Vol. 58(1).

CARD, D. \& DELLAVIGNA, S. 2013. Nine Facts about Top Journals in Economics. Journal of Economic Literature, 51, 144-161.

DE JANVRY, A. \& SADOULET, E. 2016. Development economics : theory and practice, London ; Routledge, Taylor \& Francis Group.

ELLISON, G. 2002. The Slowdown of the Economics Publishing Process. Journal of Political Economy, 110, 947-993.

FOURCADE, M., OLLION, E. \& ALGAN, Y. 2015. The Superiority of Economists.

HARRISS, J. 2002. The Case for Cross-Disciplinary Approaches in International Development. World Development, 30, 487-496.

HECKMAN, J. J. \& MOKTAN, S. 2018. Publishing and promotion in economics: The tyranny of the top five. Institute for New Economic Thinking Working Paper, 82.

KANBUR, R. 2002. Economics, Social Science and Development. World Development, 30, 477 486.

LOXLEY, J. 2004. What is Distinctive About International Development Studies? Canadian Journal of Development Studies / Revue canadienne d'études du développement, 25, 25-38.

MADRUEÑO, R. \& TEZANOS, S. 2018. The contemporary development discourse: Analysing the influence of development studies' journals. World Development, 109, 334-345.

MILLER, G. 1997. The impact of economics on contemporary political science. Journal Of Economic Literature, 35, 1173-1204.

PIETERS, R. \& BAUMGARTNER, H. 2002. Who talks to whom? Intra- and interdisciplinary communication of economics journals. Journal of Economic Literature, 483-509. 
TEZANOS VÁZQUEZ, S. \& SUMNER, A. 2013. Revisiting the Meaning of Development: A Multidimensional Taxonomy of Developing Countries. Journal of Development Studies, 49, $1728-1745$.

ZIAI, A. 2015. Development Discourse and Global History : From Colonialism to the Sustainable Development Goals, Florence, Taylor and Francis. 


\title{
Endnotes
}

\begin{abstract}
${ }^{1}$ The four journals include World Development, Development and Change, Third World Quarterly, and the European Journal of Development Research. It is not stated how and why these particular four journals were selected other than they were included in the SSCI in the cross-disciplinary subject category of 'planning and development.'
\end{abstract}

2 The current JEL classification system was introduced in 1991.
${ }^{3}$ To classify JEL codes we use the established categories and remove from our analysis categories comprising less than 5 percent of the total share.
${ }^{4}$ Since articles can reference more than one field the share of total JEL codes is greater than one and for both development economics and development studies has risen over the sample period.

${ }^{5}$ Data obtained through personal correspondence with the Editor.

\footnotetext{
${ }^{6}$ Results are available upon request. In addition, we ran a robust-check of authors identifying with either an economics or a business affiliation and the results are qualitatively unchanged. From 1990-2018, the total number of 'Business' affiliations is 286 compared to 1878 for economics affiliations.
} 
Table 1. Disciplines and their core journals

\begin{tabular}{|c|c|c|c|c|}
\hline Disciplines and their core journals & $\begin{array}{c}\text { Impact } \\
\text { factor } \\
\text { (5-year } \\
\text { average) }\end{array}$ & $\begin{array}{l}\text { Total } \\
\text { cites }\end{array}$ & $\begin{array}{c}\text { Year } \\
\text { established }\end{array}$ & $\begin{array}{c}\text { Indexed } \\
\text { by WoS } \\
\text { from } \\
\text { year } \\
\end{array}$ \\
\hline \multicolumn{5}{|l|}{ Development Economics (DE) } \\
\hline Journal of Development Economics (JDE) & 4.00 & 8,391 & 1974 & 1976 \\
\hline World Bank Research Observer (WBRO) & 4.00 & 1,360 & 1986 & 1993 \\
\hline World Bank Economic Review (WBER) & 2.27 & 2,586 & 1986 & 1986 \\
\hline $\begin{array}{l}\text { Economic Development and Cultural Change } \\
\text { (EDCC) }\end{array}$ & 2.44 & 2,537 & 1952 & 1956 \\
\hline Review of Development Economics (RDE) & 0.87 & 995 & 1997 & 2005 \\
\hline \multicolumn{5}{|l|}{ Development Studies (DS) } \\
\hline World Development (WD) & 4.61 & 19,090 & 1973 & 1976 \\
\hline Development and Change (DC) & 2.46 & 3,441 & 1970 & 1970 \\
\hline Journal of Development Studies (JDS) & 2.07 & 4,009 & 1964 & 1964 \\
\hline $\begin{array}{l}\text { Journal of Human Development and Capabilities } \\
\text { (JHDC) }\end{array}$ & 1.99 & 526 & 2000 & 2009 \\
\hline Development Policy Review (DPR) & 1.93 & 1,396 & 1966 & 2006 \\
\hline \multicolumn{5}{|l|}{ Anthropology } \\
\hline American Ethnologist & 3.30 & 3,207 & 1974 & 1980 \\
\hline Current Anthropology & 3.38 & 5,963 & 1959 & 1960 \\
\hline American Anthropologist & 2.66 & 4,944 & 1888 & 1956 \\
\hline Annual Review of Anthropology & 4.76 & 4,810 & 1959 & 1972 \\
\hline Cultural Anthropology & 4.37 & 2,595 & 1986 & 1989 \\
\hline \multicolumn{5}{|l|}{ Economics } \\
\hline Quarterly Journal of Economics & 14.15 & 28,500 & 1886 & 1956 \\
\hline Econometrica & 6.72 & 35,295 & 1933 & 1933 \\
\hline Journal of Political Economy & 7.08 & 25,790 & 1892 & 1956 \\
\hline Review of Economic Studies & 6.54 & 13,674 & 1933 & 1956 \\
\hline American Economic Review & 7.05 & 55,340 & 1911 & 1956 \\
\hline \multicolumn{5}{|l|}{ Geography } \\
\hline $\begin{array}{l}\text { Global Environmental Change - Human and Policy } \\
\text { Dimensions }\end{array}$ & 11.22 & 17,370 & 1990 & 1990 \\
\hline Economic Geography & 8.69 & 3,351 & 1925 & 1956 \\
\hline Progress in Human Geography & 7.53 & 7,098 & 1977 & 1982 \\
\hline Journal of Economic Geography & 5.35 & 4,230 & 2001 & 2002 \\
\hline Cambridge Journal of Regions Economy and Society & 4.81 & 1,492 & 2008 & 2008 \\
\hline \multicolumn{5}{|l|}{ Political Science } \\
\hline International Organization & 5.66 & 7,262 & 1947 & 1956 \\
\hline American Journal of Political Science & 7.32 & 12,069 & 1956 & 1973 \\
\hline Annual Review of Political Science & 6.19 & 3,666 & 1998 & 1998 \\
\hline
\end{tabular}




\begin{tabular}{lrrrr}
\hline Disciplines and their core journals & $\begin{array}{c}\text { Impact } \\
\text { factor } \\
\text { (5-year } \\
\text { average) }\end{array}$ & $\begin{array}{l}\text { Total } \\
\text { cites }\end{array}$ & $\begin{array}{c}\text { Year } \\
\text { established }\end{array}$ & $\begin{array}{c}\text { Indexed } \\
\text { by WoS } \\
\text { from } \\
\text { year }\end{array}$ \\
\hline American Political Science Review & 6.63 & 14,993 & 1906 & 1956 \\
British Journal of Political Science & 4.72 & 3,983 & 1971 & 1971 \\
\hline Sociology & & & & \\
American Sociological Review & 7.38 & 20,192 & 1936 & 1956 \\
American Journal of Sociology & 5.90 & 19,544 & 1895 & 1956 \\
British Journal of Sociology & 3.52 & 3,308 & 1950 & 1956 \\
Social Problems & 3.44 & 4,591 & 1953 & 1956 \\
European Sociological Review & 3.44 & 3,712 & 1985 & 1993 \\
\hline
\end{tabular}

Source: Authors' compilation of SSCI data on journals

Notes: WoS stands for Web of Science. SSCI stands for Social Science Citation Index. 


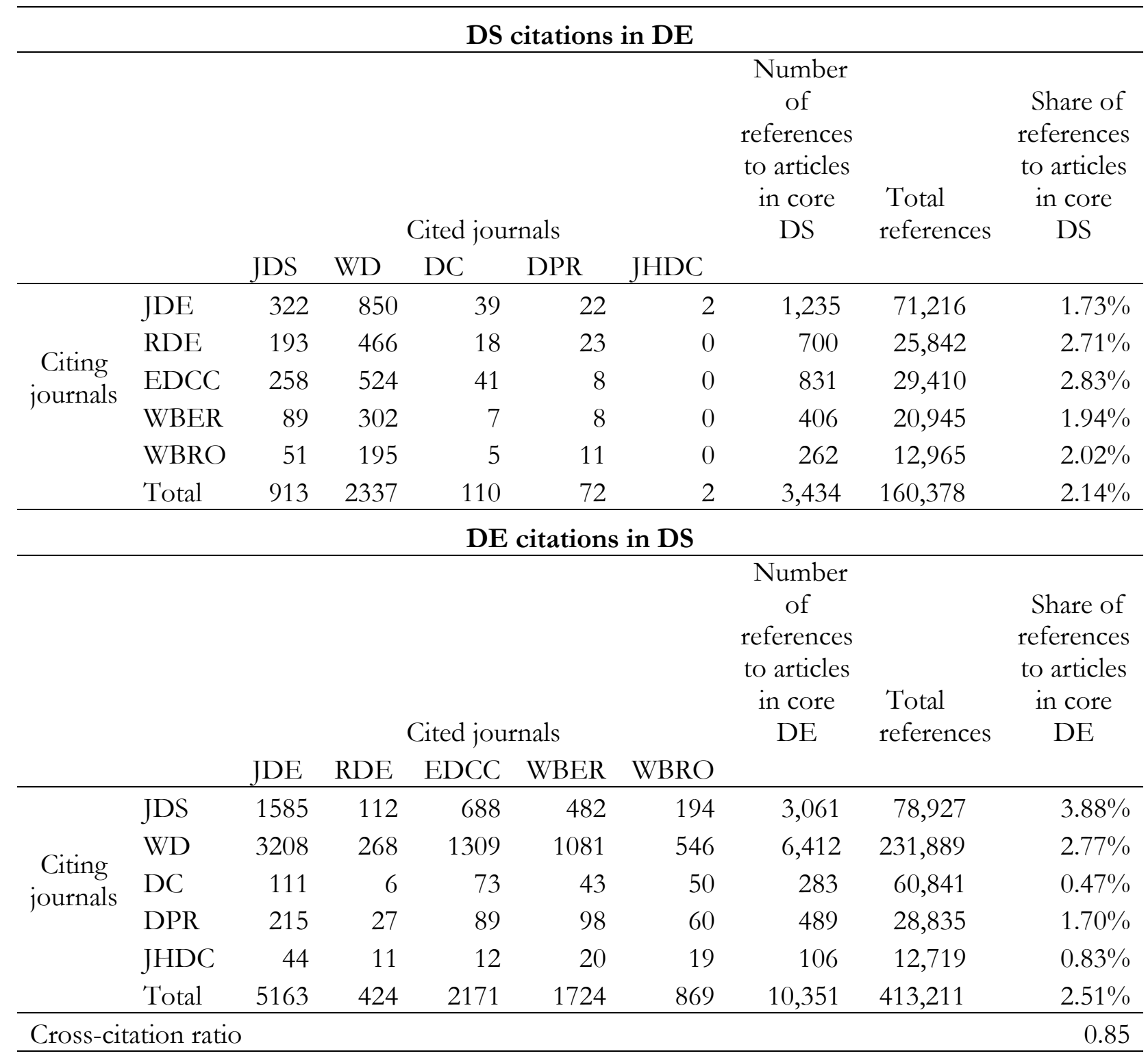

Source: Authors' calculations based on WoS citation data 


\begin{tabular}{|c|c|c|c|c|c|c|c|c|c|}
\hline \multicolumn{10}{|c|}{ DS citations in DE } \\
\hline \multirow{2}{*}{\multicolumn{2}{|c|}{ 2010-2018 }} & \multicolumn{5}{|c|}{ Cited journals } & \multirow[t]{2}{*}{$\begin{array}{l}\text { Number } \\
\text { of } \\
\text { references } \\
\text { to articles } \\
\text { in core DS }\end{array}$} & \multirow[t]{2}{*}{$\begin{array}{l}\text { Total } \\
\text { references }\end{array}$} & \multirow[t]{2}{*}{$\begin{array}{c}\text { Share of } \\
\text { references } \\
\text { to articles } \\
\text { in core } \\
\text { DS }\end{array}$} \\
\hline & & JDS & WD & $\mathrm{DC}$ & DPR & JHDC & & & \\
\hline \multirow{6}{*}{$\begin{array}{l}\text { Citing } \\
\text { journals }\end{array}$} & JDE & 144 & 400 & 19 & 17 & 2 & 582 & 35,662 & $1.63 \%$ \\
\hline & $\mathrm{RDE}$ & 105 & 285 & 11 & 15 & 0 & 416 & 17,046 & $2.44 \%$ \\
\hline & EDCC & 89 & 137 & 5 & 6 & 0 & 237 & 9,201 & $2.58 \%$ \\
\hline & WBER & 49 & 168 & 4 & 5 & 0 & 226 & 8,996 & $2.51 \%$ \\
\hline & WBRO & 28 & 131 & 3 & 10 & 0 & 172 & 6,293 & $2.73 \%$ \\
\hline & Total & 415 & 1121 & 42 & 53 & 2 & 1,633 & 77,198 & $2.12 \%$ \\
\hline \multirow{2}{*}{\multicolumn{2}{|c|}{$2000-2009$}} & & & & & & & & \\
\hline & & JDS & WD & $\mathrm{DC}$ & DPR & JHDC & & & \\
\hline \multirow{6}{*}{$\begin{array}{l}\text { Citing } \\
\text { journals }\end{array}$} & JDE & 113 & 240 & 13 & 3 & 0 & 369 & 20,784 & $1.78 \%$ \\
\hline & $\mathrm{RDE}$ & 50 & 79 & 6 & 5 & 0 & 140 & 5,700 & $2.46 \%$ \\
\hline & EDCC & 91 & 200 & 16 & 1 & 0 & 308 & 10,199 & $3.02 \%$ \\
\hline & WBER & 22 & 71 & 2 & 0 & 0 & 95 & 5,744 & $1.65 \%$ \\
\hline & WBRO & 18 & 32 & 1 & 1 & 0 & 52 & 3,806 & $1.37 \%$ \\
\hline & Total & 294 & 622 & 38 & 10 & 0 & 964 & 46,233 & $2.09 \%$ \\
\hline \multicolumn{2}{|c|}{ 1990-1999 } & JDS & WD & $\mathrm{DC}$ & DPR & JHDC & & & \\
\hline \multirow{6}{*}{$\begin{array}{l}\text { Citing } \\
\text { journals }\end{array}$} & JDE & 53 & 169 & 4 & 1 & 0 & 227 & 12,343 & $1.84 \%$ \\
\hline & RDE & 0 & 0 & 0 & 0 & 0 & - & - & \#DIV/0! \\
\hline & EDCC & 67 & 162 & 18 & 0 & 0 & 247 & 8,955 & $2.76 \%$ \\
\hline & WBER & 14 & 55 & 1 & 0 & 0 & 70 & 5,708 & $1.23 \%$ \\
\hline & WBRO & 5 & 32 & 1 & 0 & 0 & 38 & 2,866 & $1.33 \%$ \\
\hline & Total & 139 & 418 & 24 & 1 & 0 & 582 & 29,872 & $1.95 \%$ \\
\hline
\end{tabular}

DE citations in DS

$2010-2018$

\begin{tabular}{|c|c|c|}
\hline \multirow{2}{*}{\multicolumn{3}{|c|}{ Number }} \\
\hline & & \\
\hline $\begin{array}{c}\text { of } \\
\text { references }\end{array}$ & & Share of \\
\hline to articles & & to articles \\
\hline $\begin{array}{c}\text { in core } \\
\text { DE }\end{array}$ & $\begin{array}{l}\text { Total } \\
\text { references }\end{array}$ & $\begin{array}{c}\text { in core } \\
\text { DE }\end{array}$ \\
\hline
\end{tabular}

Cited journals

JDE RDE WBER WBRO EDCC

\begin{tabular}{clrrrrrrrr}
\hline \multirow{5}{*}{ Citing } & JDS & 848 & 79 & 255 & 103 & 372 & 1,657 & 42,025 & $3.94 \%$ \\
journals & DC & 1948 & 208 & 630 & 312 & 701 & 3,799 & 117,022 & $3.25 \%$ \\
& DPR & 38 & 5 & 13 & 21 & 21 & 98 & 27,955 & $0.35 \%$ \\
& JHDC & 37 & 23 & 70 & 38 & 69 & 356 & 21,311 & $1.67 \%$ \\
& & 9 & 18 & 17 & 9 & 90 & 10,815 & $0.83 \%$
\end{tabular}




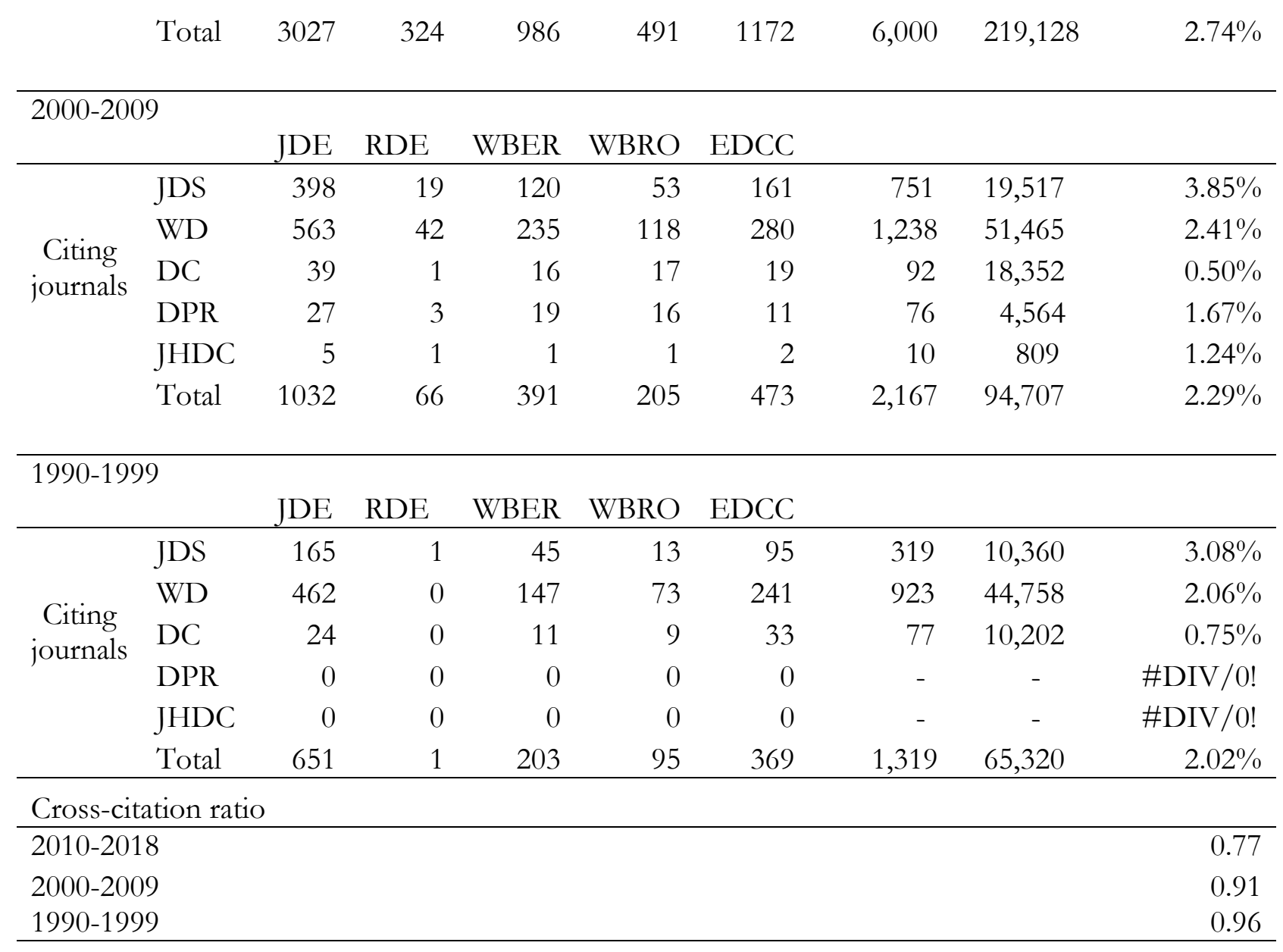

Source: Authors' calculations based on WoS citation data 
Figure 1a: Number of Social Science citations found in DE, 1990-2018

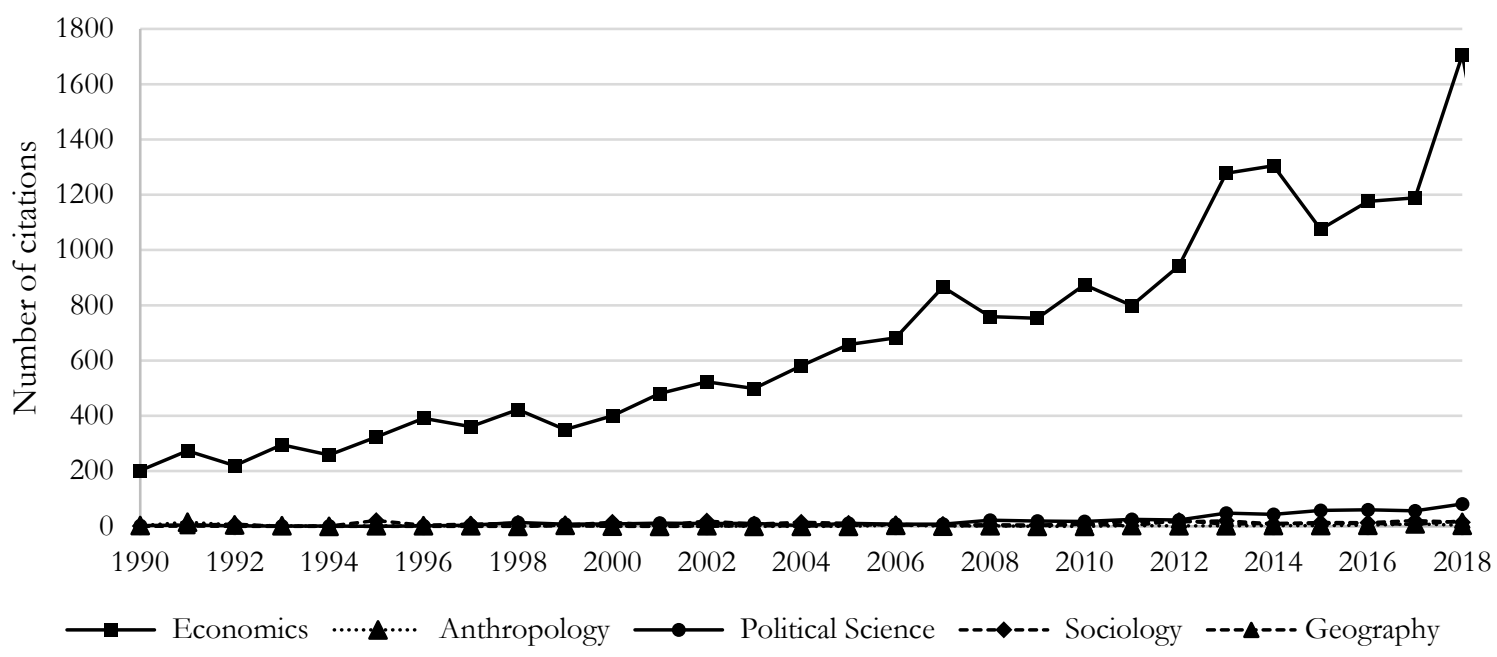

Figure 1b: Number of Social Science citations found in DS, 1990-2018

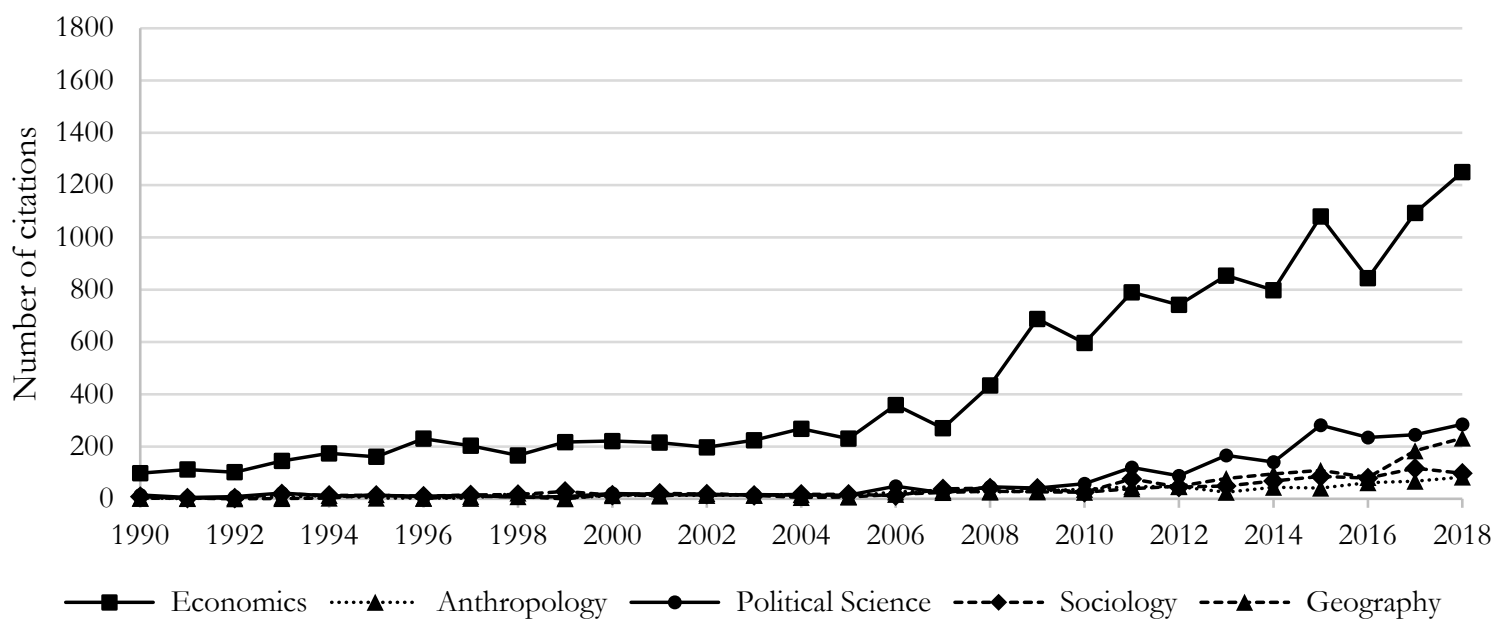


Figure 2a: DE citations in the Social Sciences, 1990-2018

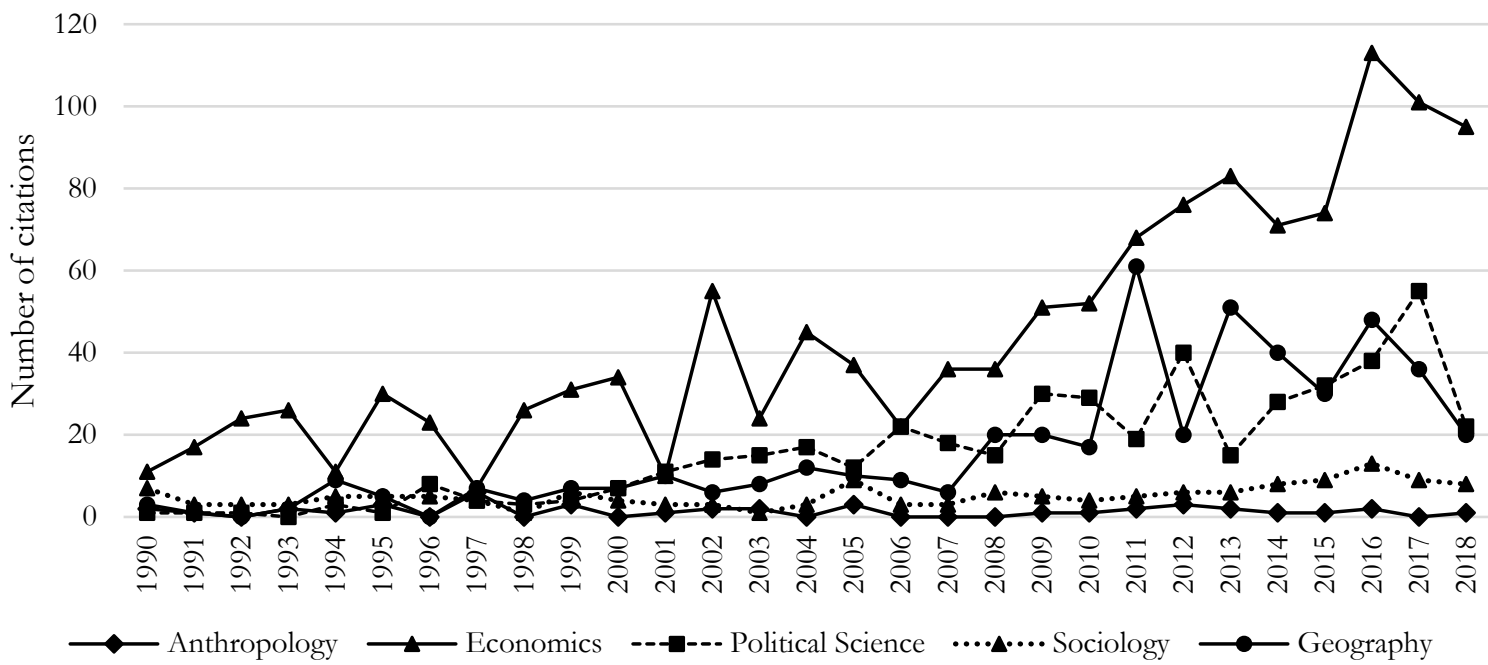

Figure 2b: DS citations in the Social Sciences, 1990-2018

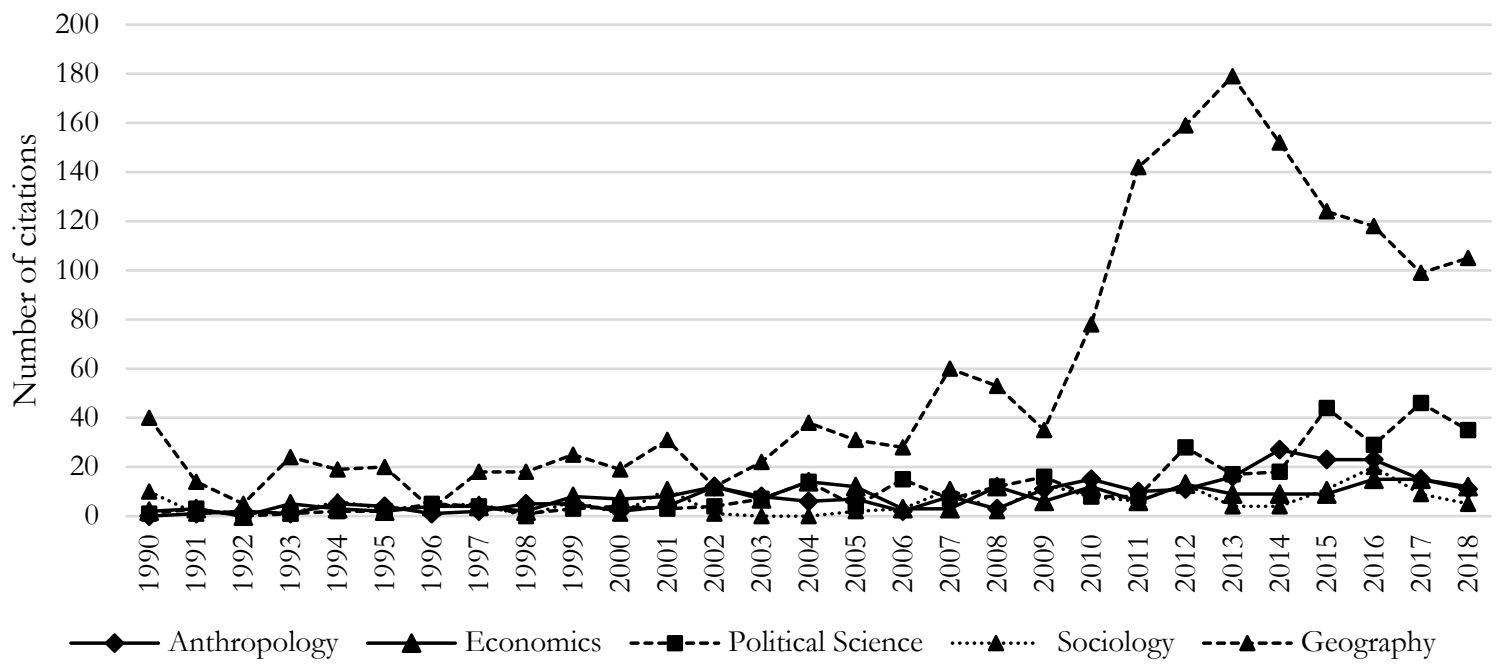


Figure 3a: DS citations in DE by DE journals, 1990-2018

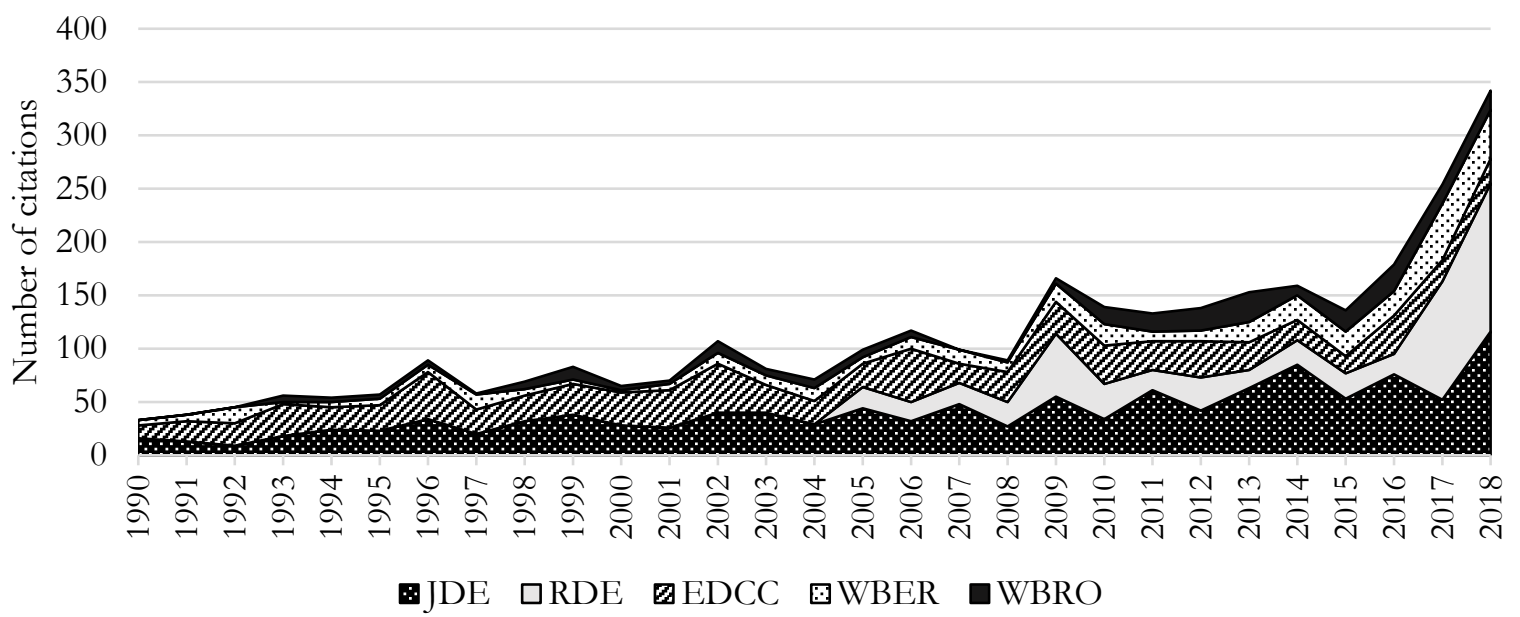

Figure 3b: DS citations in DE by DS journals, 1990-2018

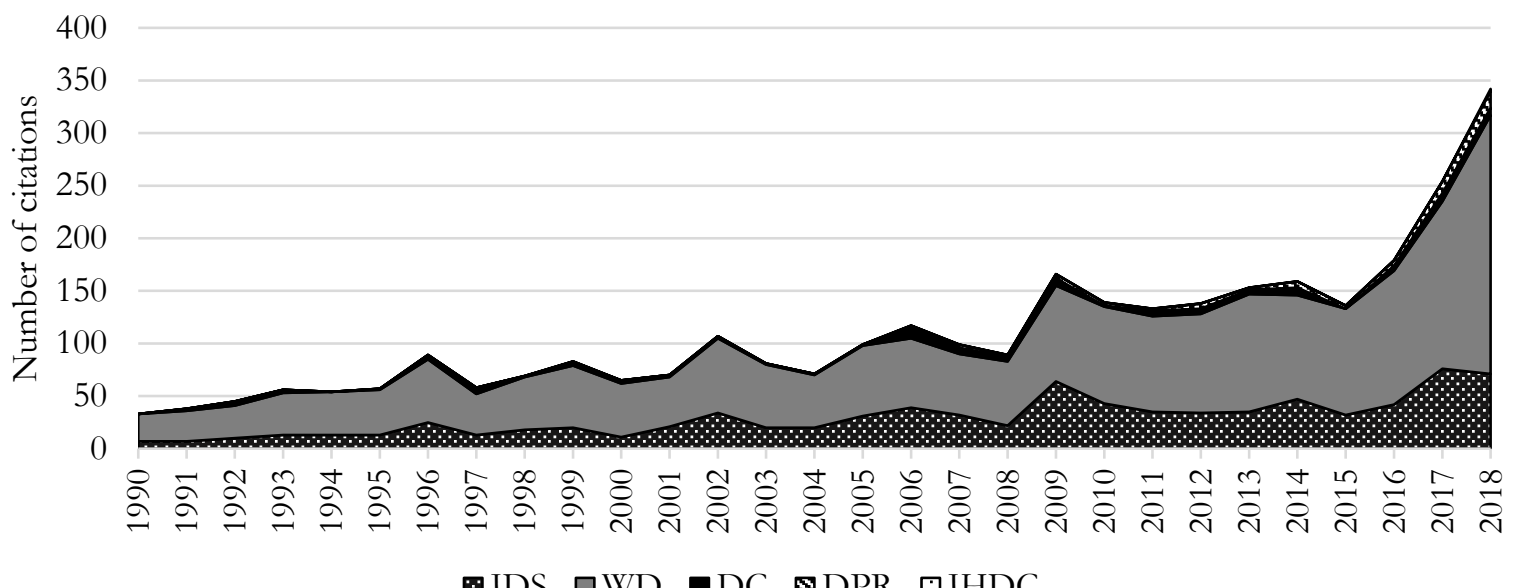

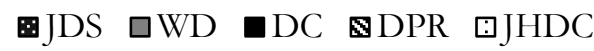


Figure 3c: DE citations in DS by DE journals, 1990-2018

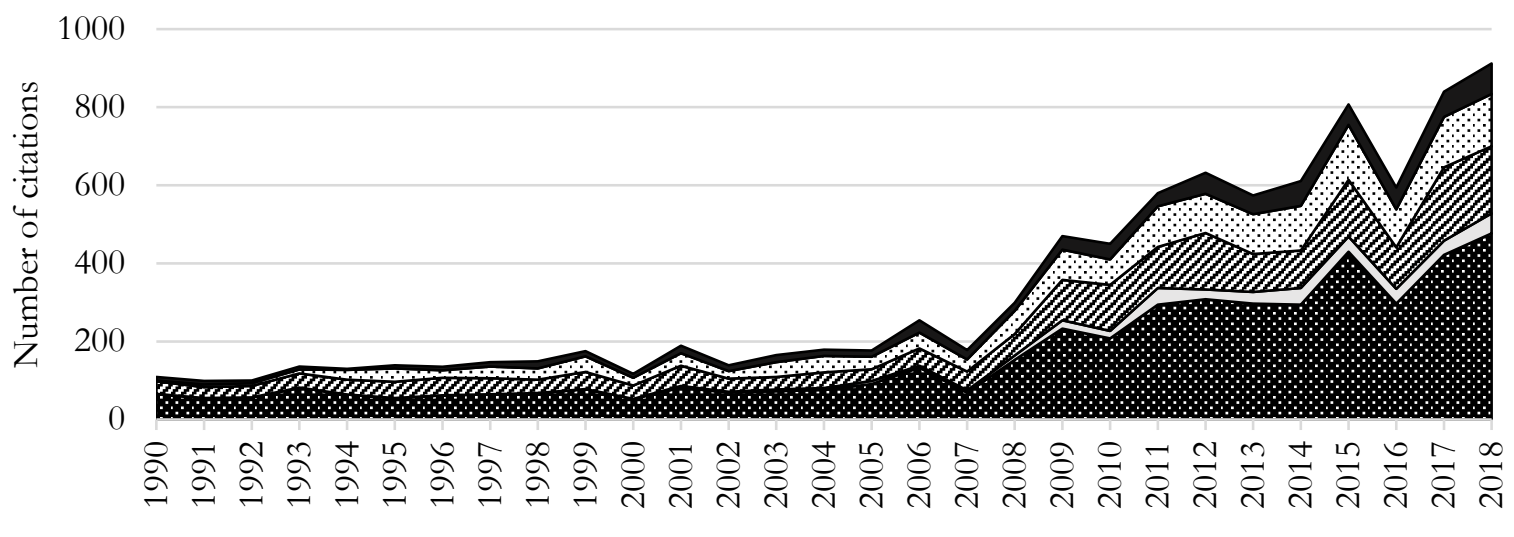

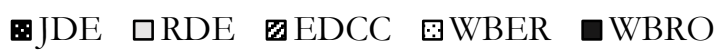

Figure 3d: DE citations in DS by DS journals, 1990-2018

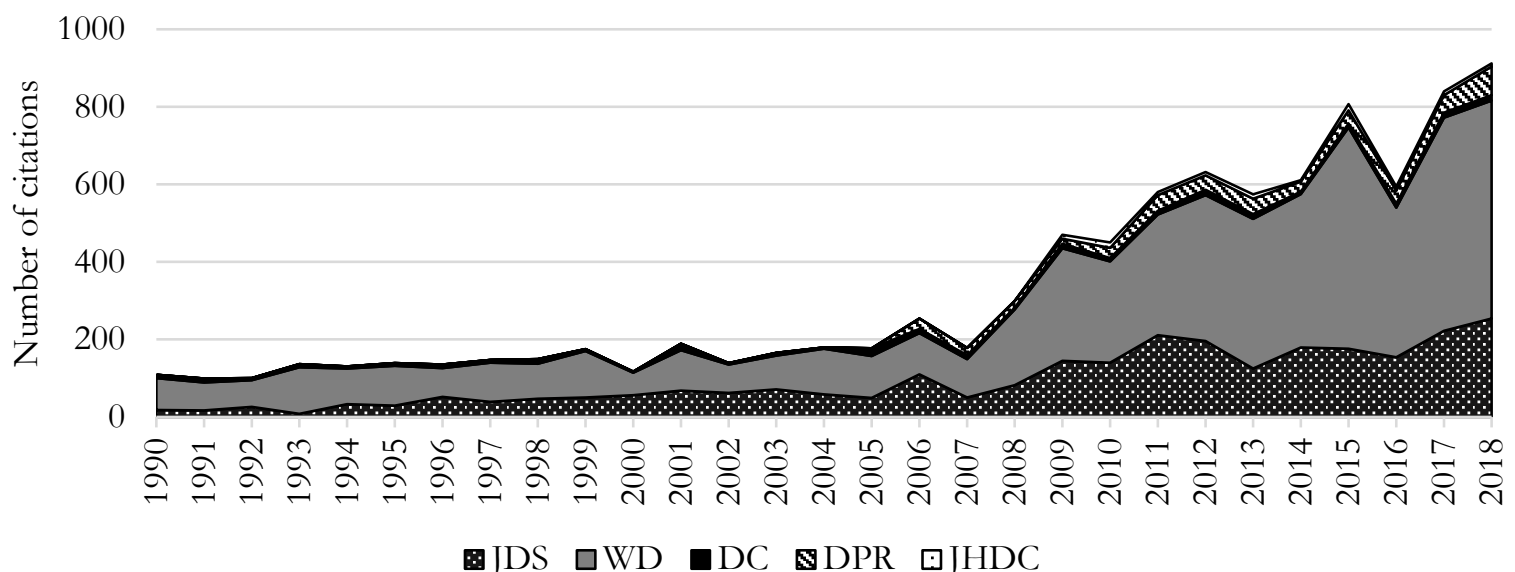

Figure 3e: Cross citation ratio

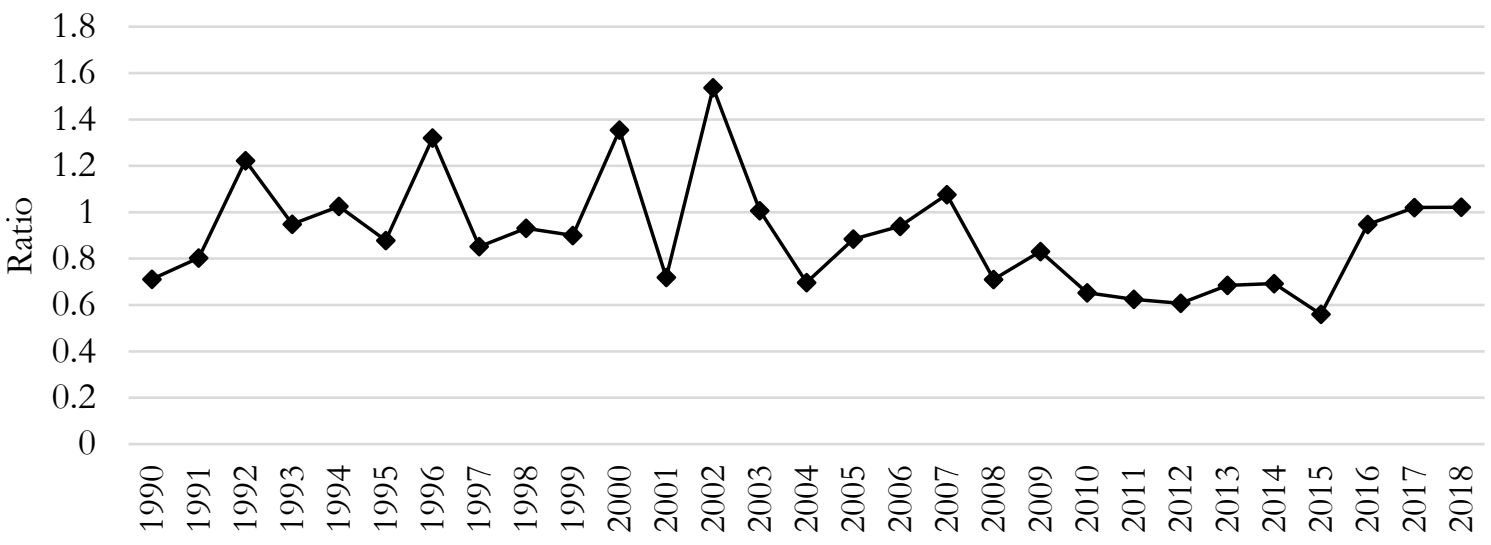


Figure 4a: Share of DE Articles Published by Field of Research, 1991-2018

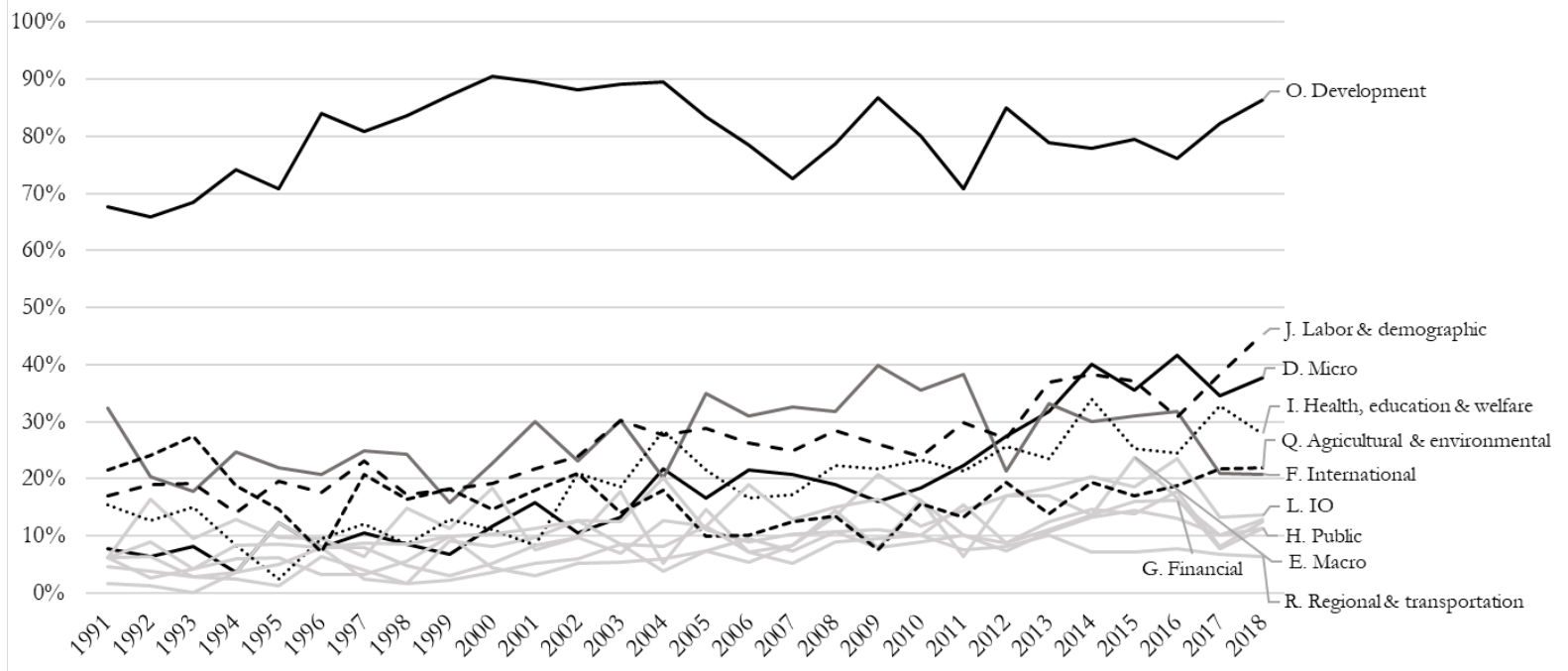

Figure 4b: Share of DS Articles Published by Field of Research, 1991-2018

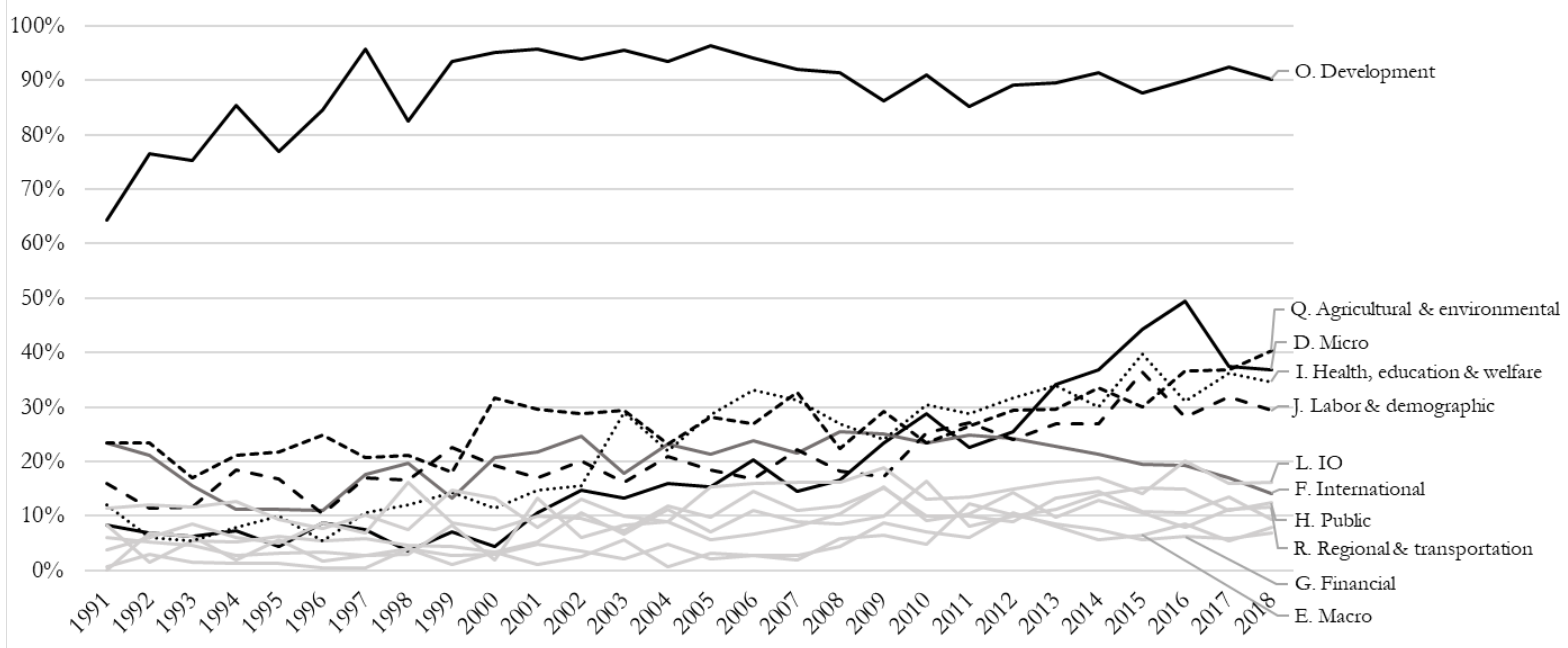


Figure 5: Article Acceptance Rates at Select Development Journals

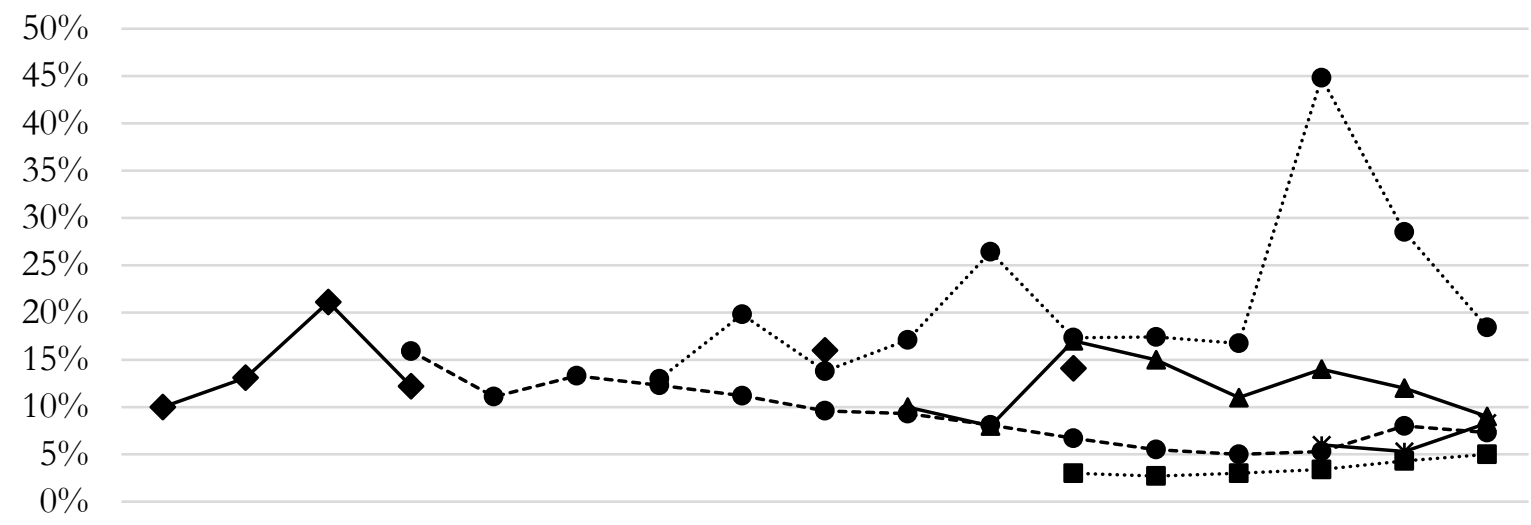

19901995200020052006200720082009201020112012201320142015201620172018

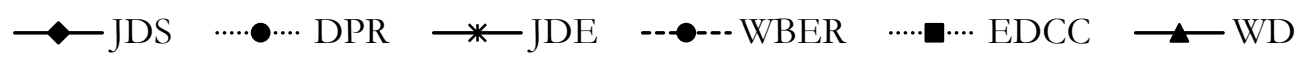

Figure 6: Total citations in DE and DS, 1990-2018

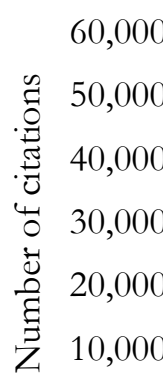

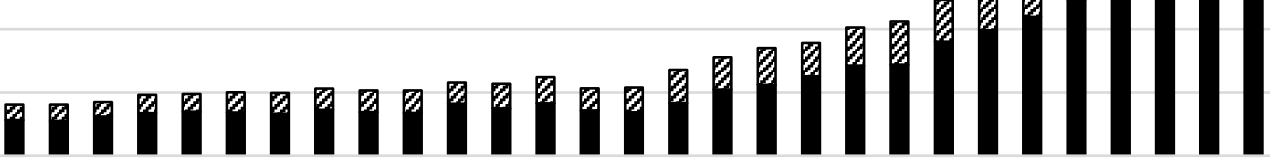

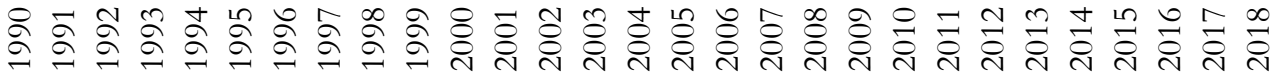

-Top 5 Development Studies

Top 5 Development Economics

Figure 7. Number of Authors with Economics Affiliations in DS by journal, 1990-2018

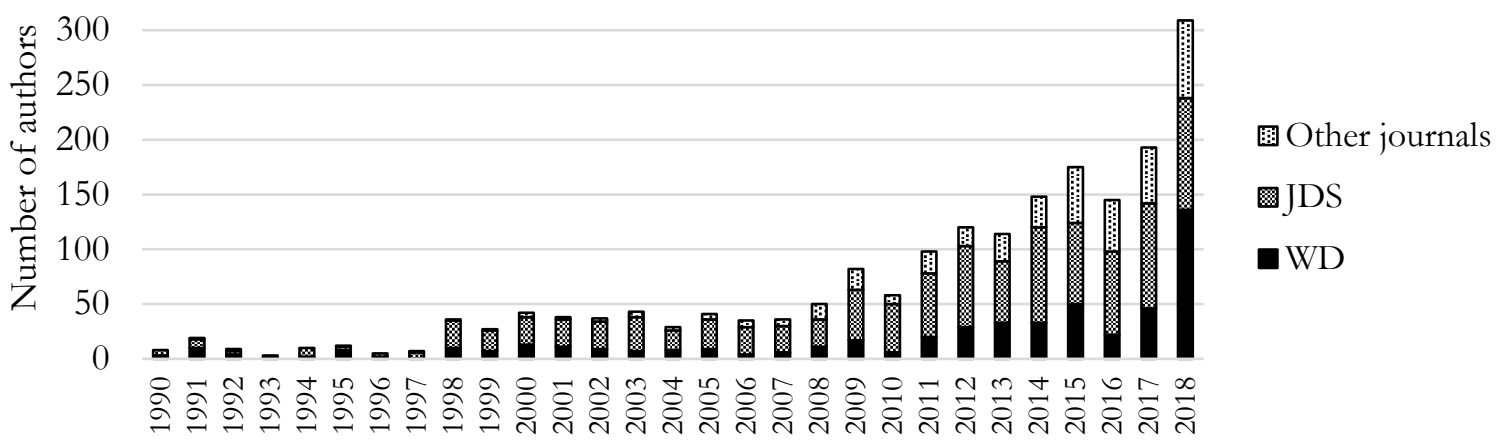




\section{Appendix}

Table 1

\begin{tabular}{|c|c|c|c|c|}
\hline Journals in Development Studies & $\begin{array}{l}\text { Impact } \\
\text { factor } \\
\text { (5-year } \\
\text { average } \\
\text { ) }\end{array}$ & $\begin{array}{l}\text { Total } \\
\text { cites }\end{array}$ & $\begin{array}{c}\text { Year } \\
\text { establishe } \\
\text { d }\end{array}$ & $\begin{array}{c}\text { Indexe } \\
\text { d by } \\
\text { WoS } \\
\text { from } \\
\text { year }\end{array}$ \\
\hline World Development (WD) & 4.61 & 19,090 & 1973 & 1976 \\
\hline Development and Change (DC) & 2.46 & 3,441 & 1970 & 1970 \\
\hline Journal of Development Studies (JDS) & 2.07 & 4,009 & 1964 & 1964 \\
\hline $\begin{array}{l}\text { Journal of Human Development and } \\
\text { Capabilities (JHDC) }\end{array}$ & 1.99 & 526 & 2000 & 2009 \\
\hline Development Policy Review (DPR) & 1.93 & 1,396 & 1966 & 2006 \\
\hline Journal of Development Effectiveness (JDEf) & 1.54 & 503 & 2009 & 2009 \\
\hline $\begin{array}{l}\text { European Journal of Development Research } \\
\text { (EJDR) }\end{array}$ & 1.52 & 1,074 & 1989 & 2009 \\
\hline Journal of International Development (JID) & 1.36 & 2,098 & 1989 & 2009 \\
\hline $\begin{array}{l}\text { Canadian Journal of Development Studies } \\
\text { (CJDS) }\end{array}$ & 1.28 & 528 & 1980 & 1980 \\
\hline Developing Economies (DE) & 0.80 & 418 & 1962 & 1963 \\
\hline Sustainable Development $(\mathrm{SD})^{\wedge}$ & 4.17 & 2257 & 1993 & 1999 \\
\hline Third World Quarterly (TWQ)^ & 2.74 & 4248 & 1979 & 1980 \\
\hline
\end{tabular}

Source: Authors' compilation of SSCI data on journals

Notes: WoS stands for Web of Science. SSCI stands for Social Science Citation Index.

Journal not indexed in EconLit

Appendix Figure 1. Annual Total Published Articles in Top 5 DE and Top 5 DS

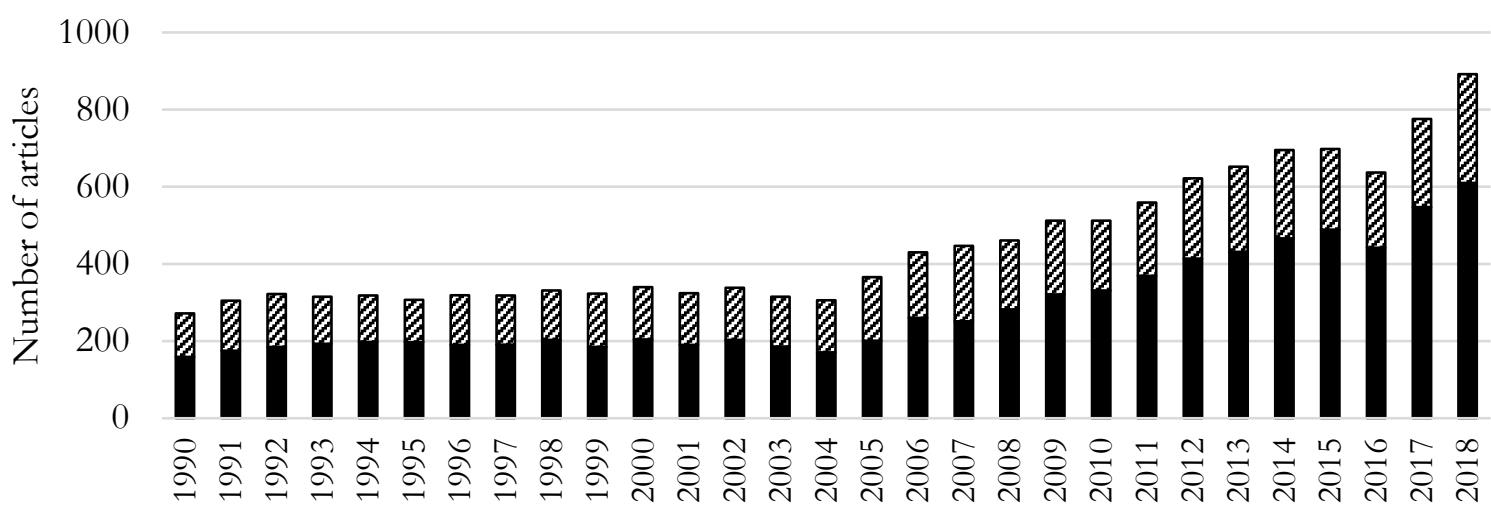

-Top 5 Development Studies

Top 5 Development Economics 
Appendix Figure 2. Average Number of Citations per Paper in Top 5 DE and Top 5 DS

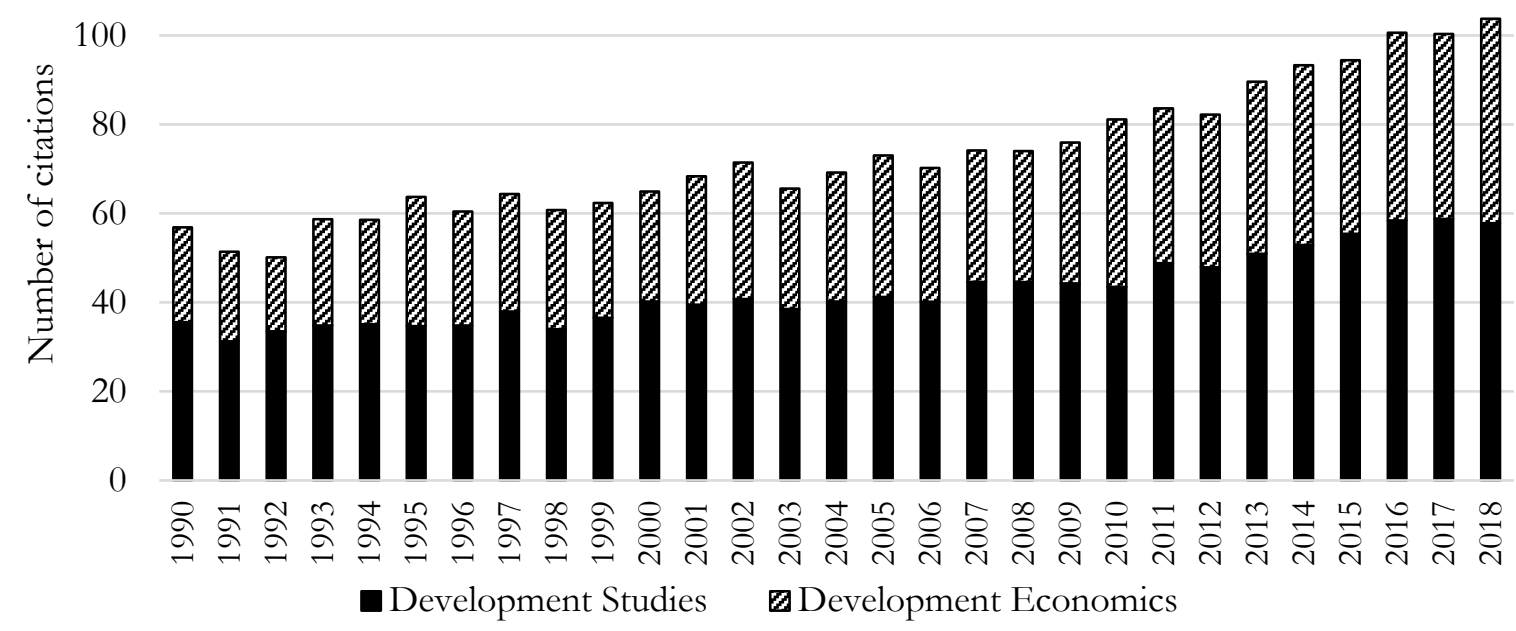

Appendix Figure 3. Annual Total Published Articles in Top 5 DS, by Journal

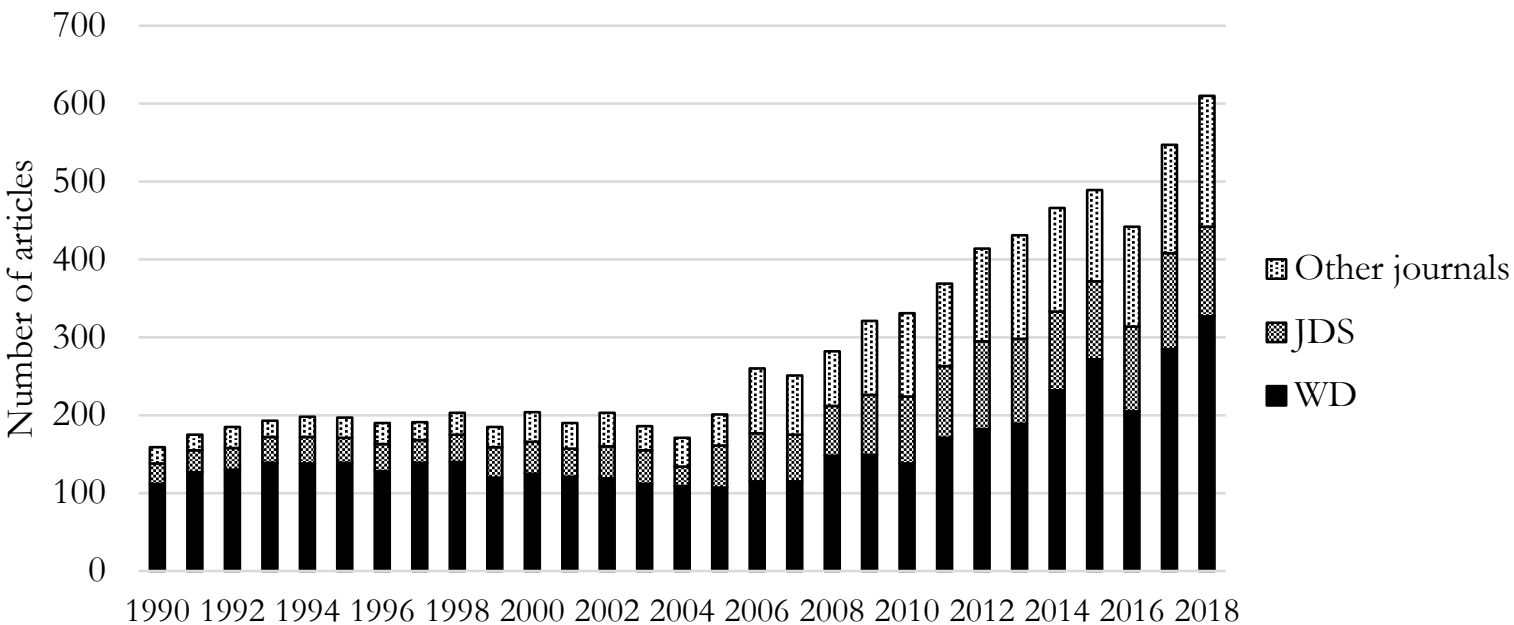


Appendix Figure 4. Number of Social Science citations found in Top 10 DS, 1990-2018

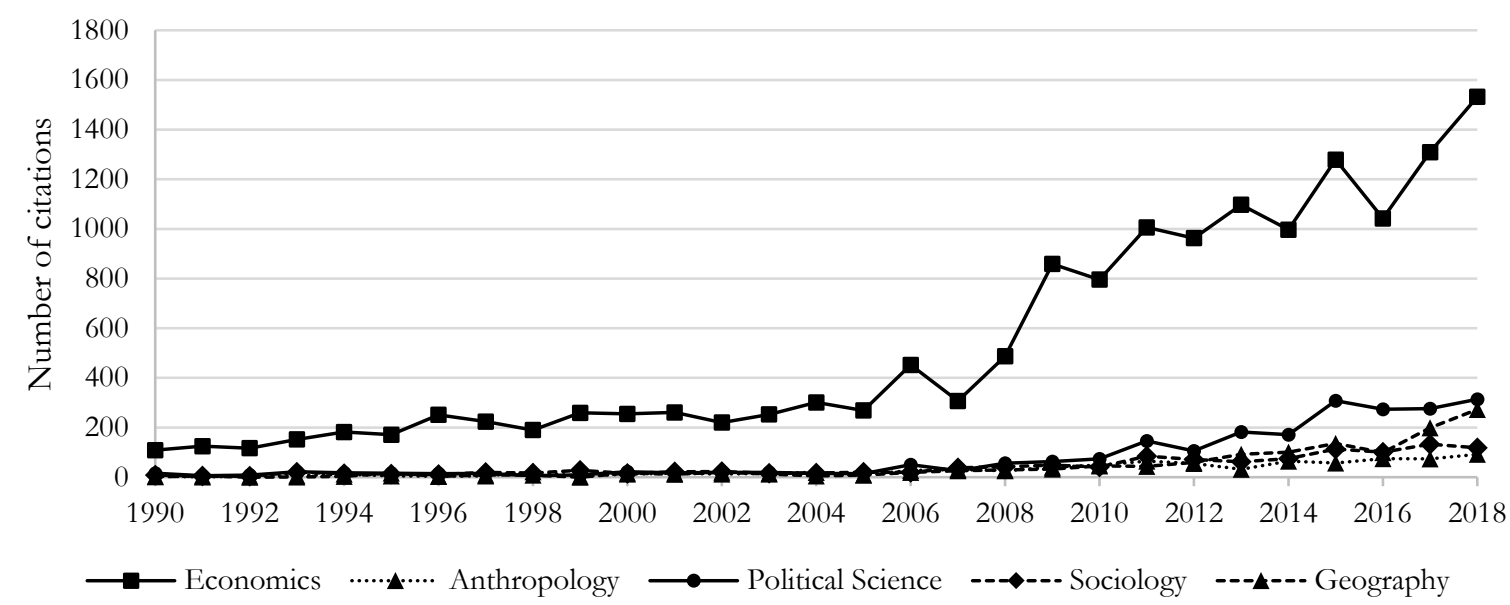

Appendix Figure 5: Top 10 DS citations in the Social Sciences, 1990-2018

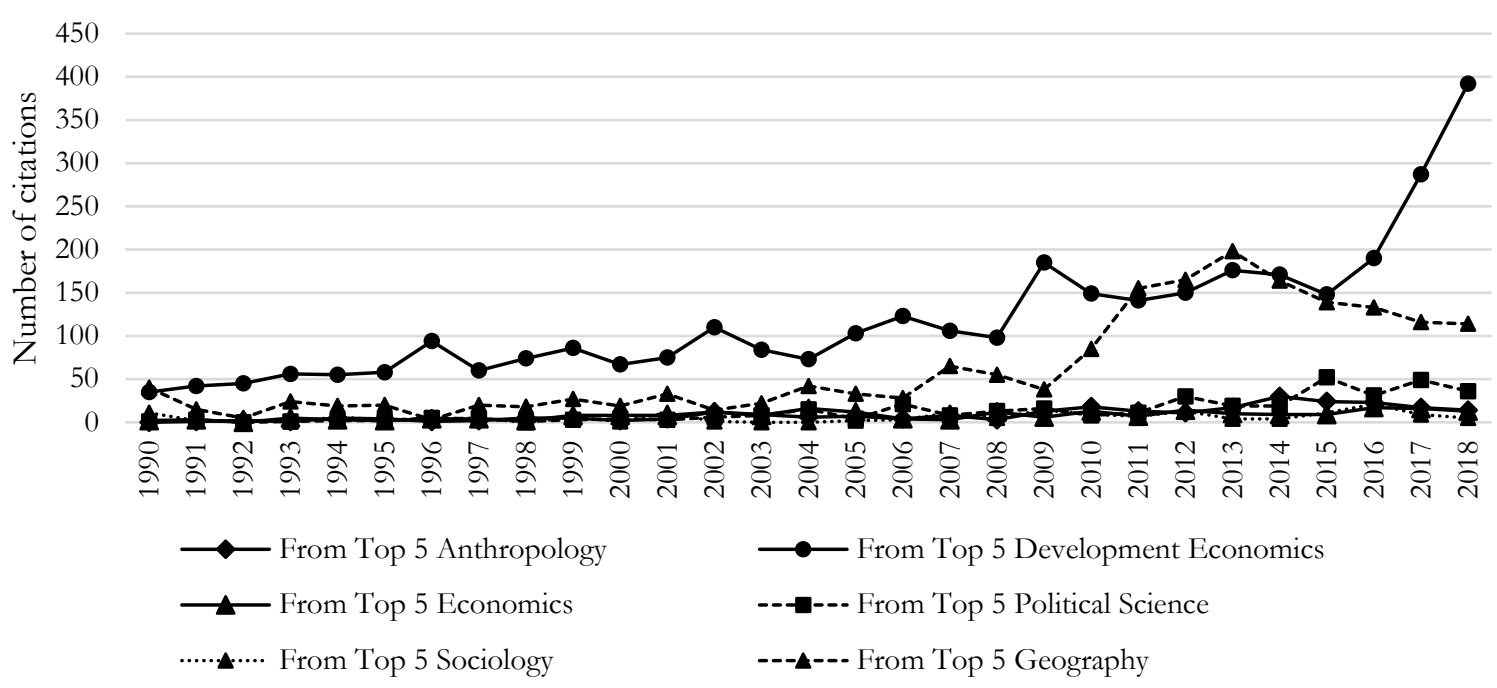


Appendix Figure 6a: Top 10 DS citations in DE by DE journals, 1990-

2018

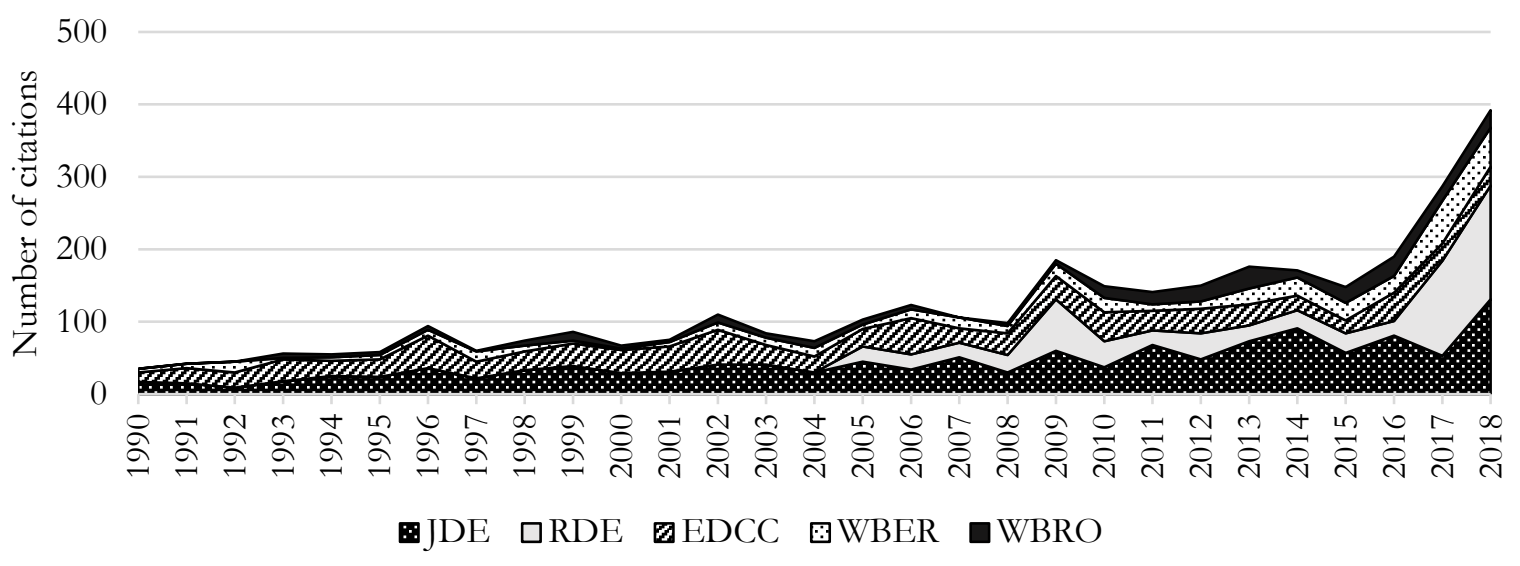

Appendix Figure 6b: Top 10 DS citations in DE by DS journals, 1990-

2018

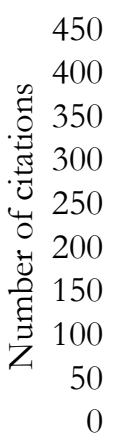

๙

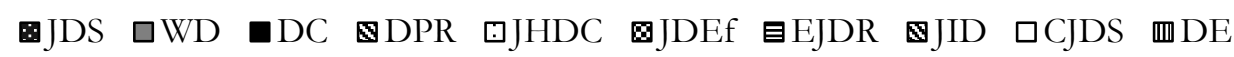

Appendix Figure 6c: DE citations in Top 10 DS by DE journals, 1990-

2018

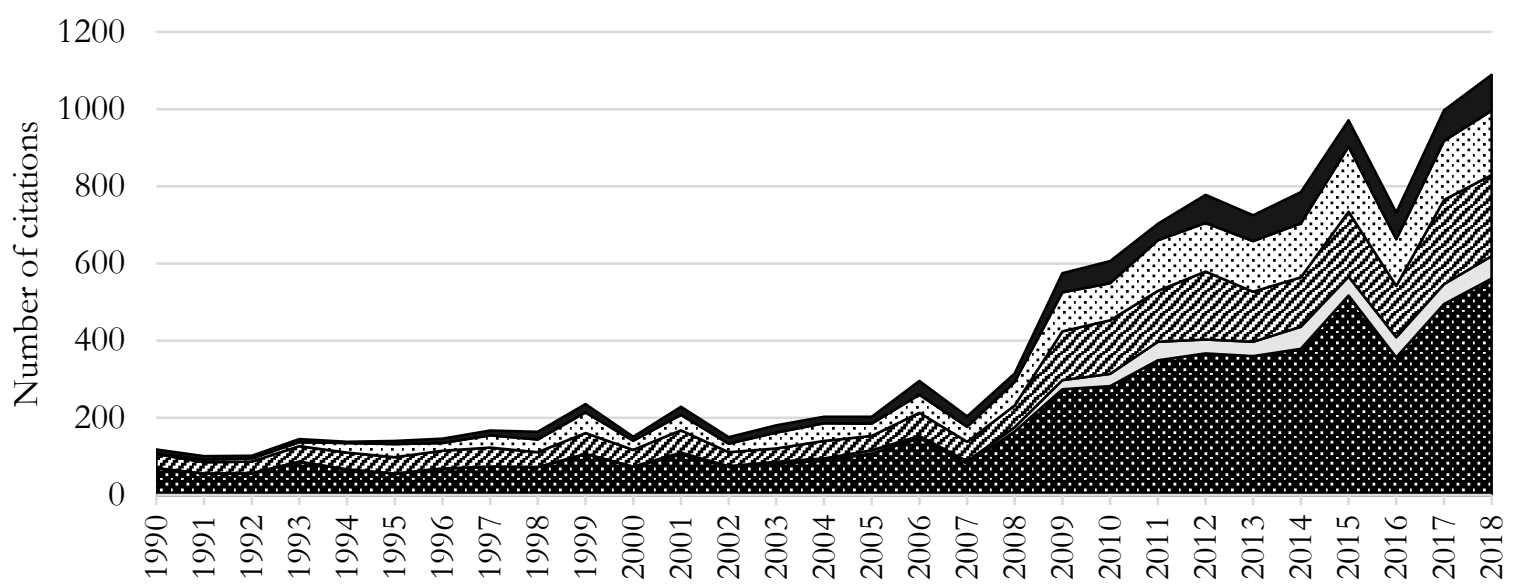

\$JDE $\square$ RDE $\square$ EDCC $⿴$ WBER $\square$ WBRO 
Appendix Figure 6d: DE citations in Top 10 DS by DS journals, 1990-

2018

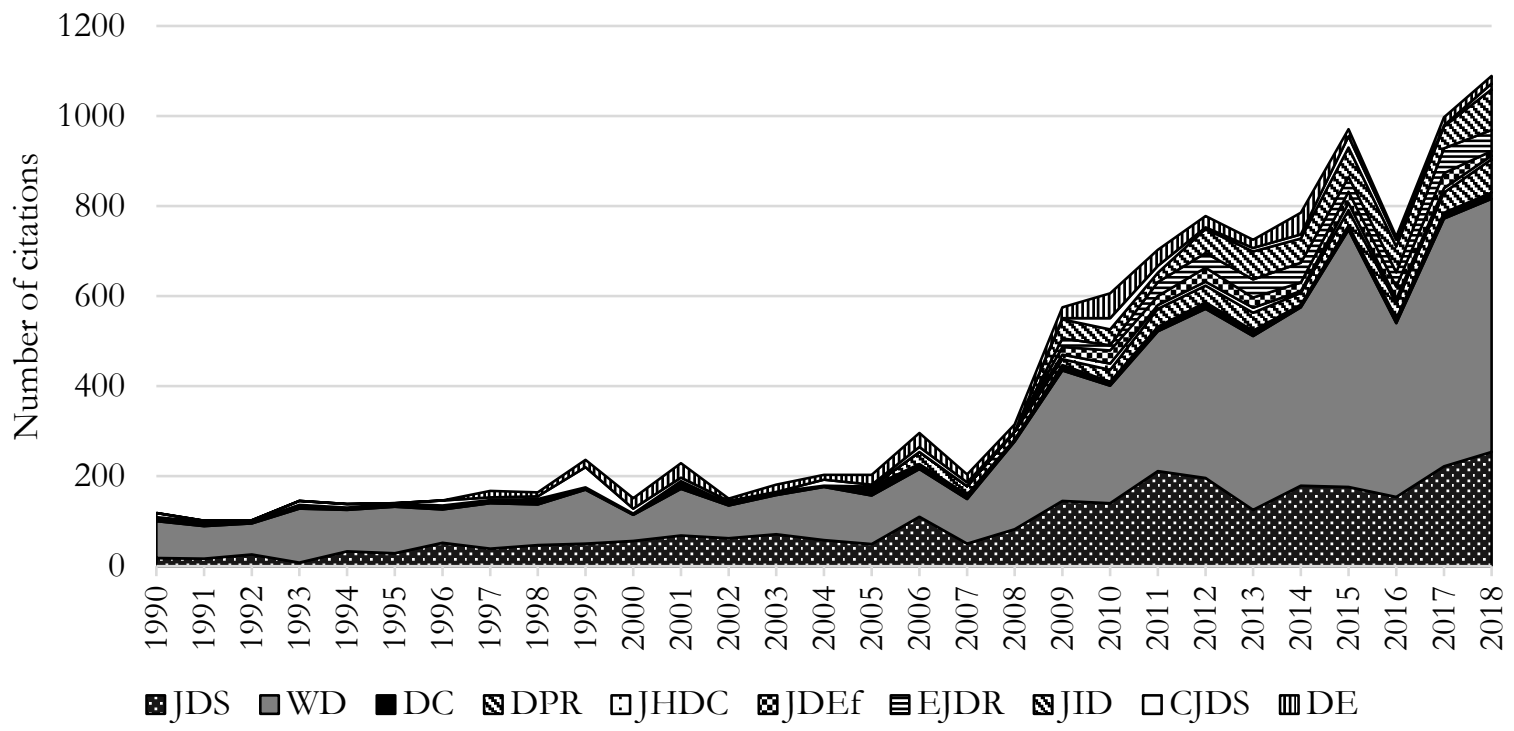

Appendix Figure 6e: Cross citation ratio (DE-Top 10 DS)

2.00

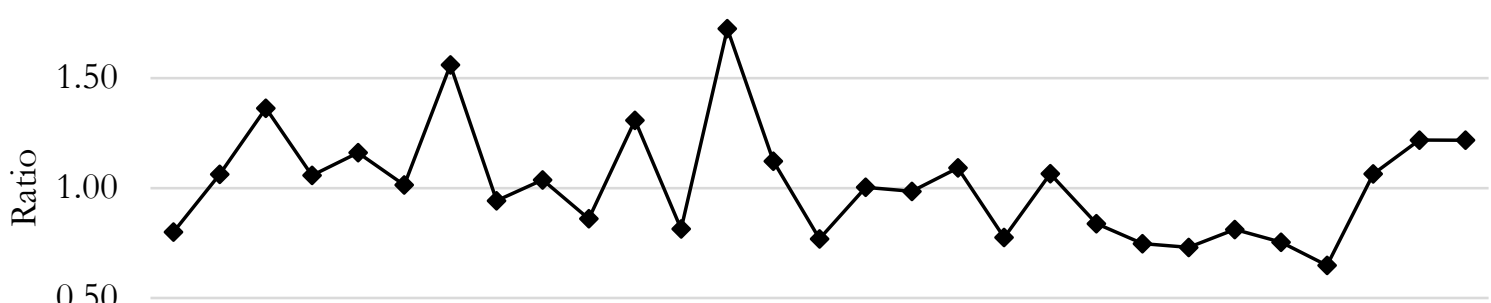

0.00

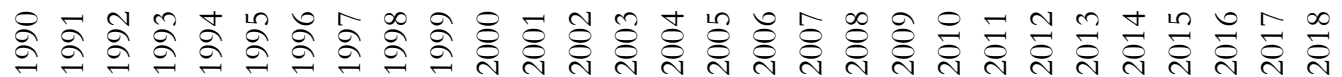

Appendix Figure 7: Total citations in DE and DS, 1990-2018

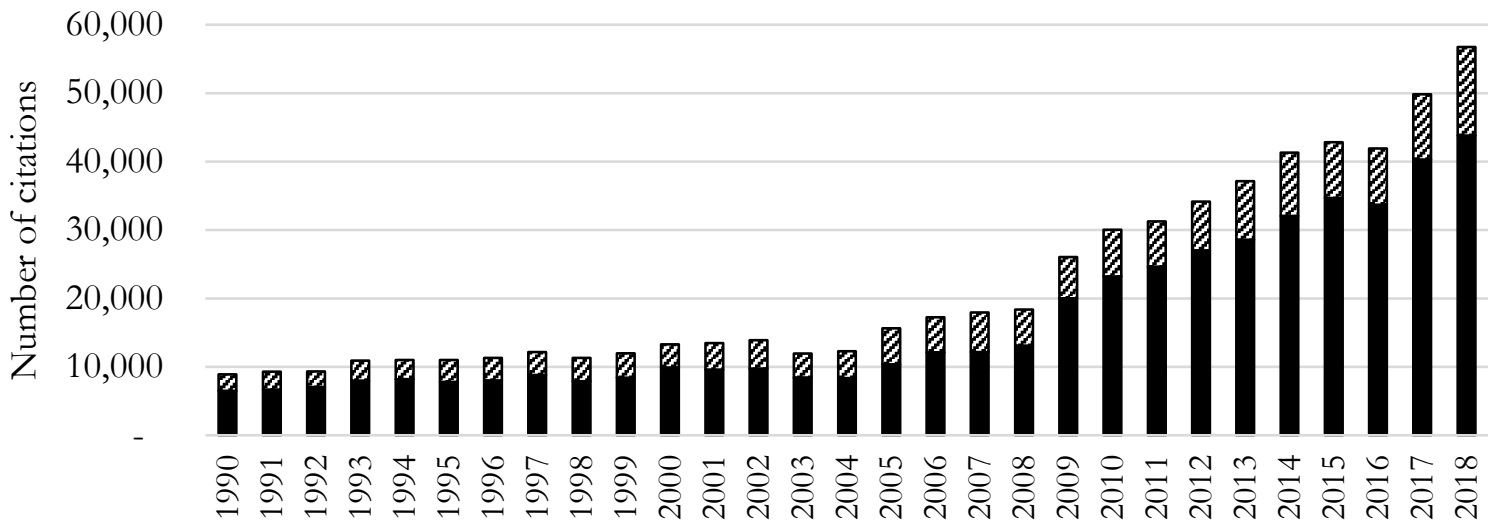

- Top 10 Development Studies

■Top 5 Development Economics 